\title{
أولا -
}

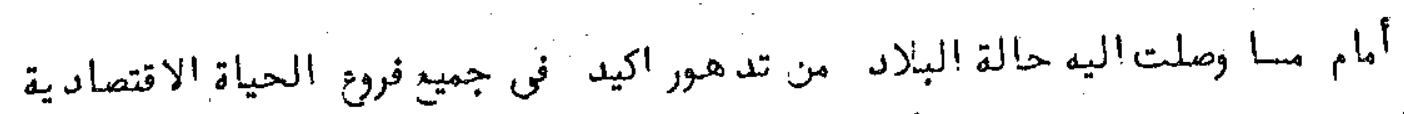

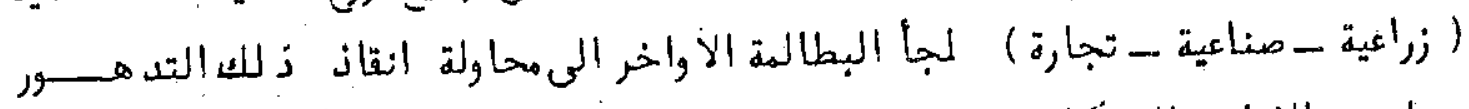

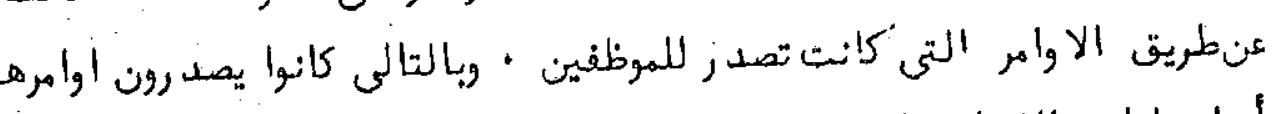

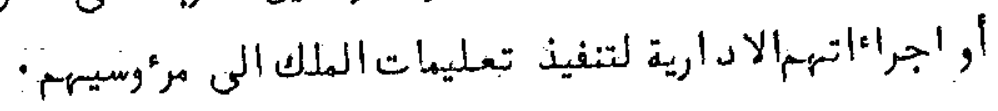

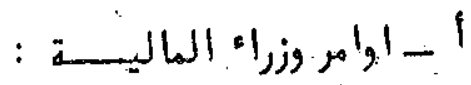

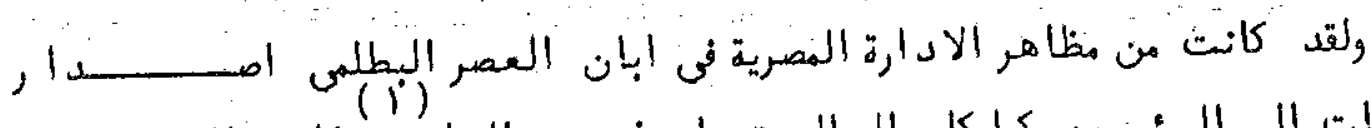

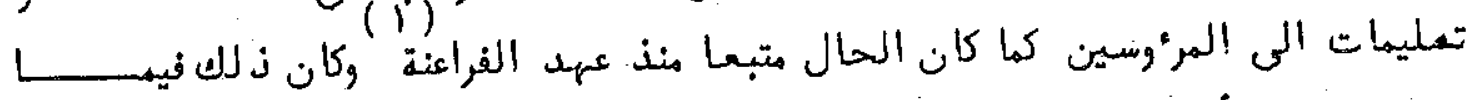

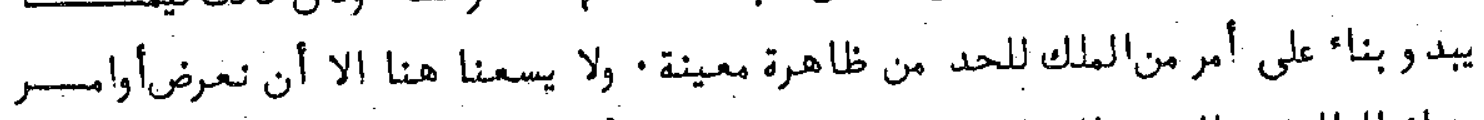

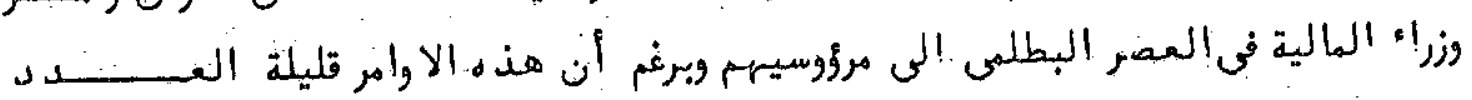

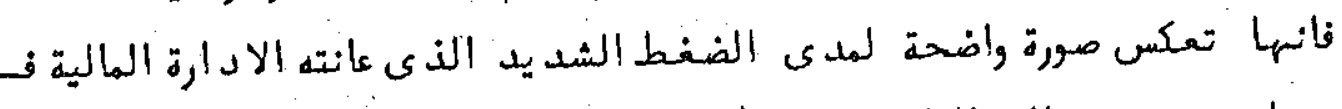

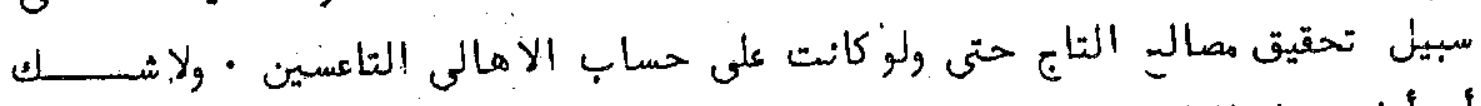

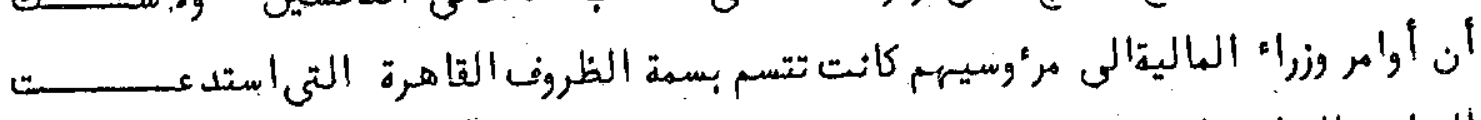

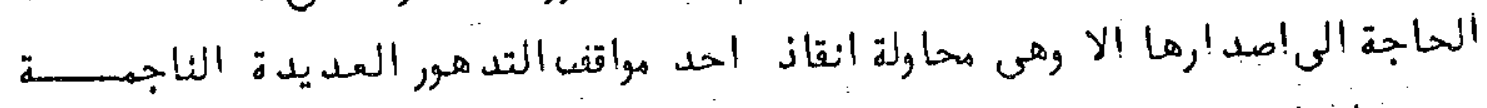

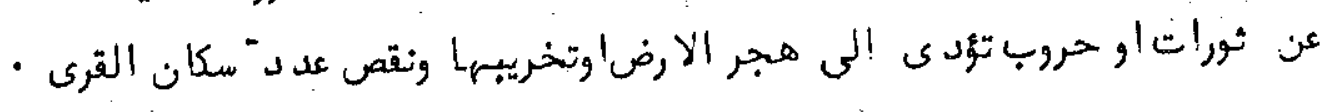

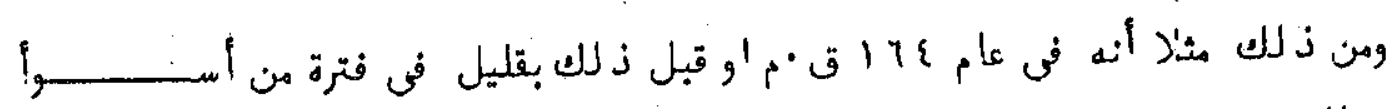

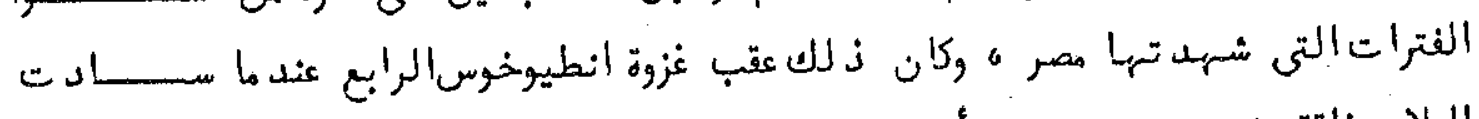

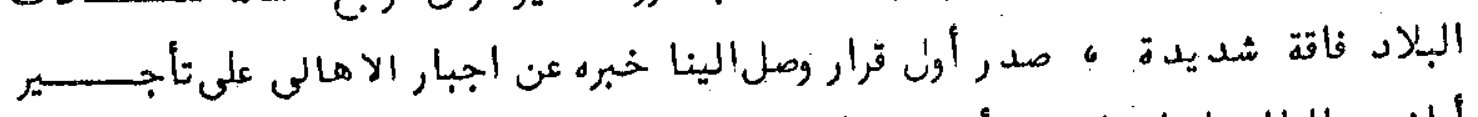

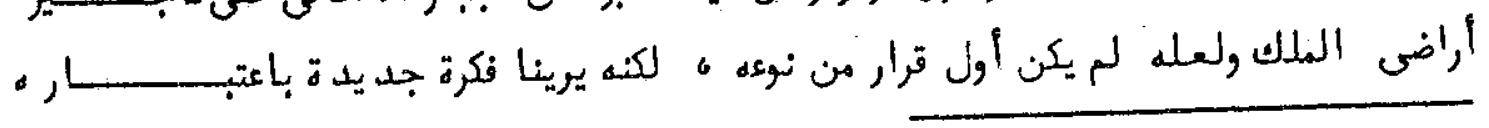

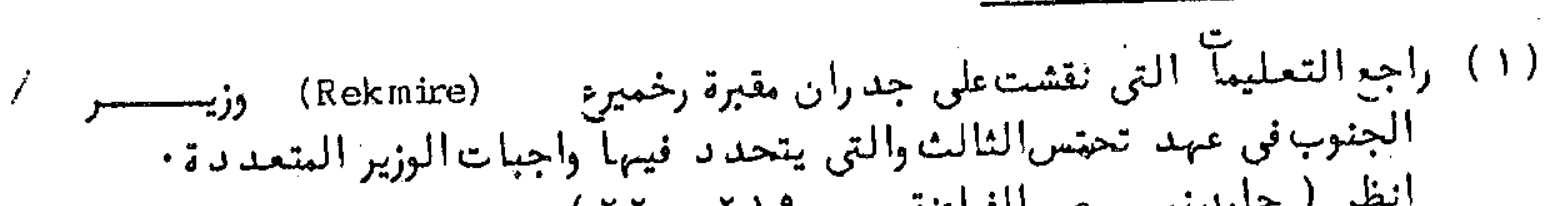

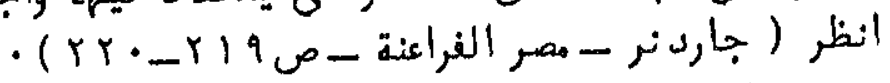




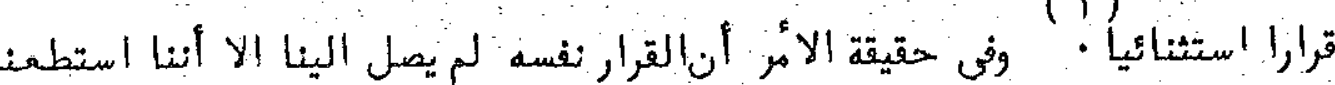

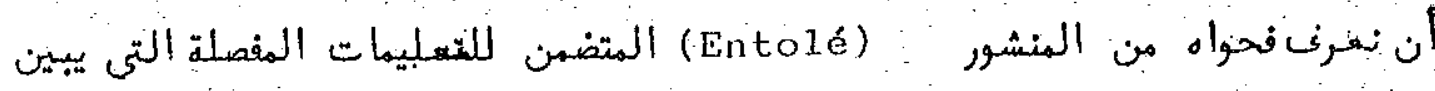

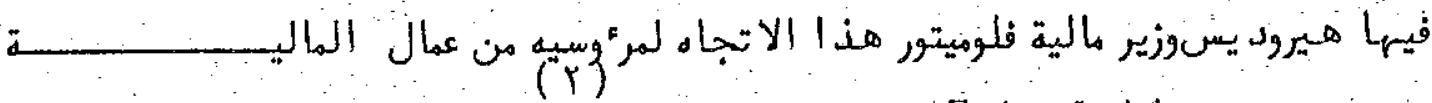
hypodioketia, Epimeletia

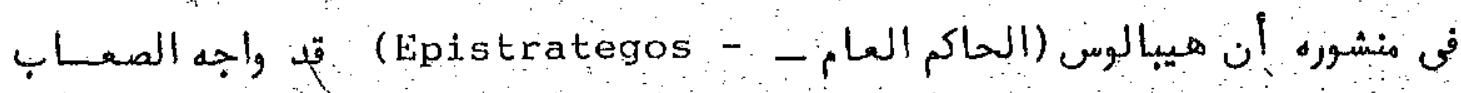

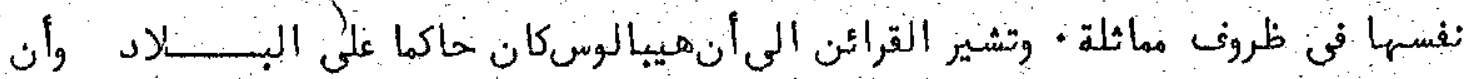
a.

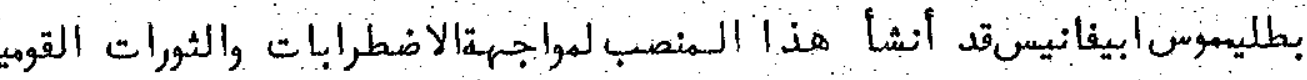

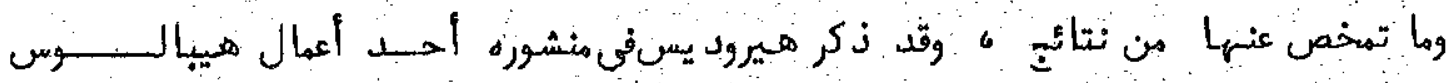

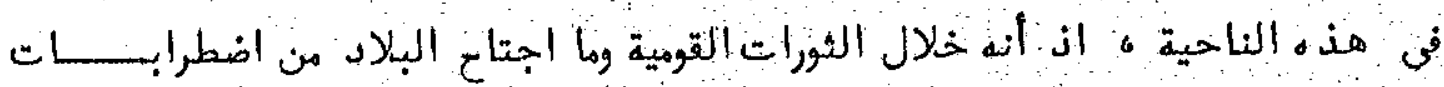

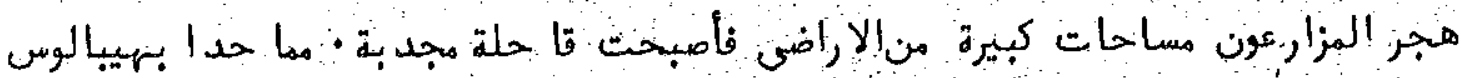

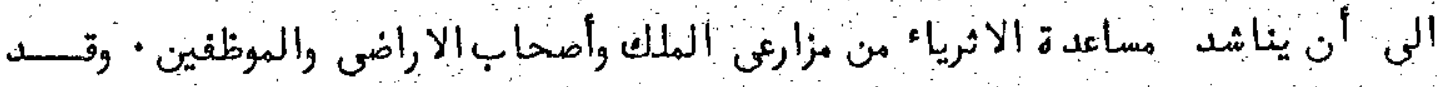

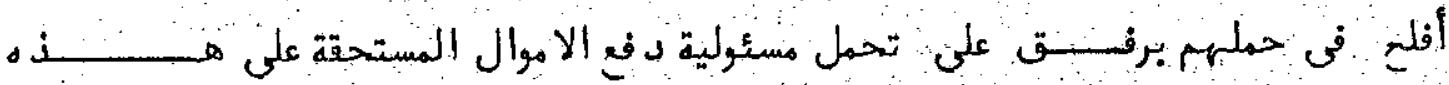

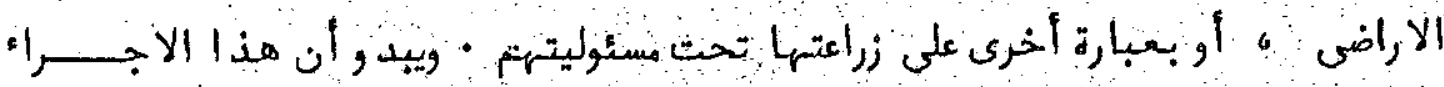
كان

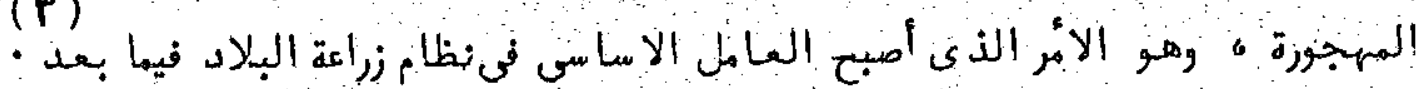

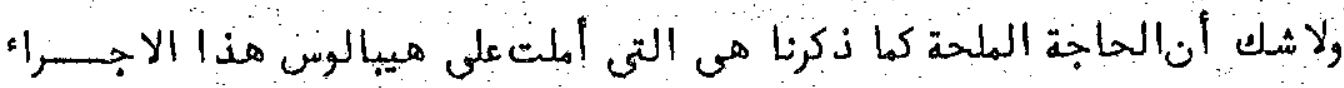

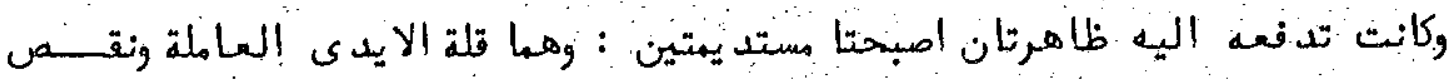

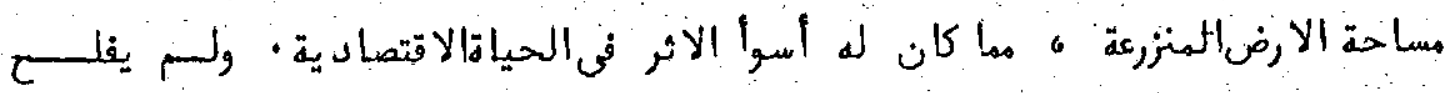

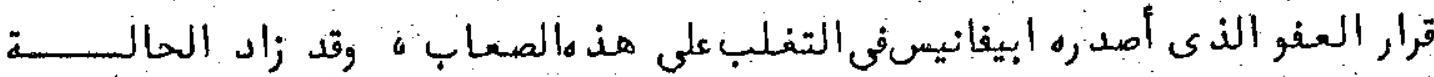

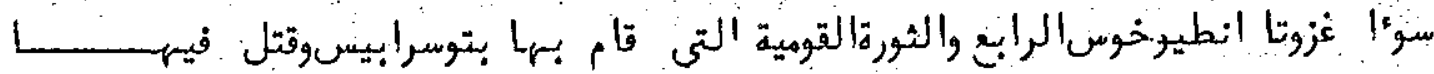

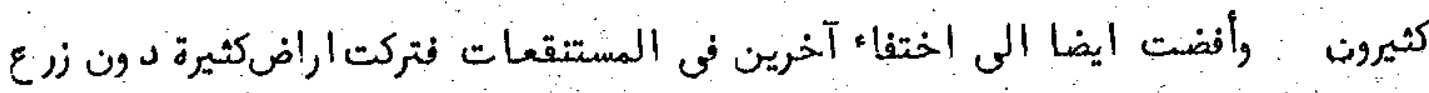

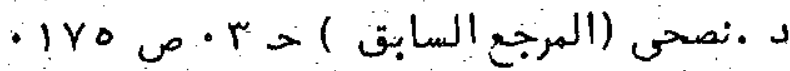

; (2) U.P.Z:, 110.

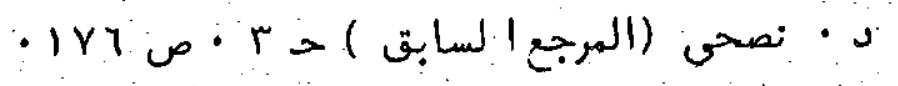


وفي العام التالى لانتهاء الثورة حدث نقصشد يد في الحبوب الغنذائية ه فكـــــان

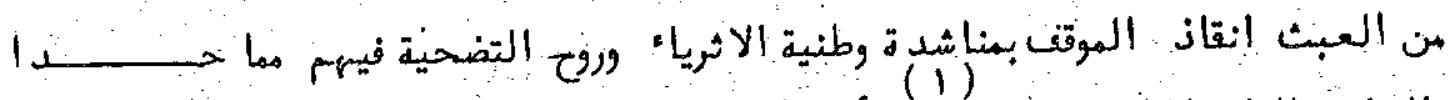

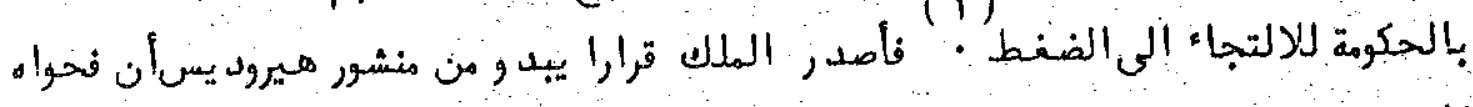

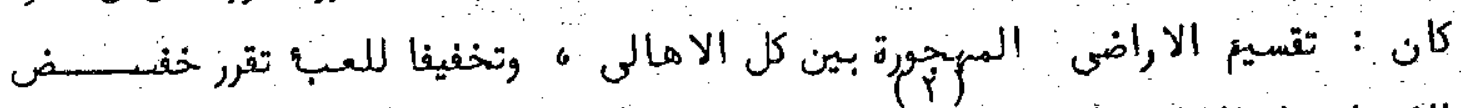

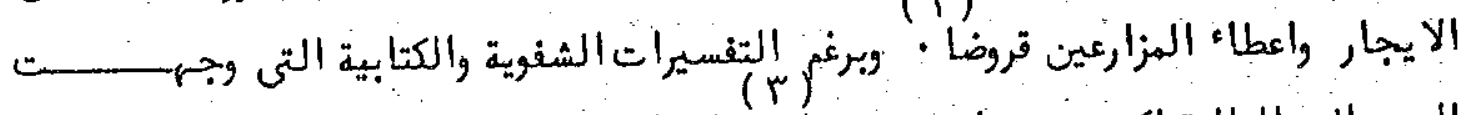

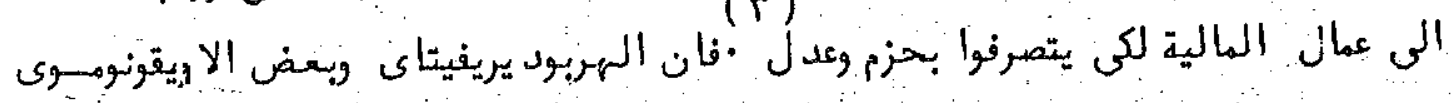

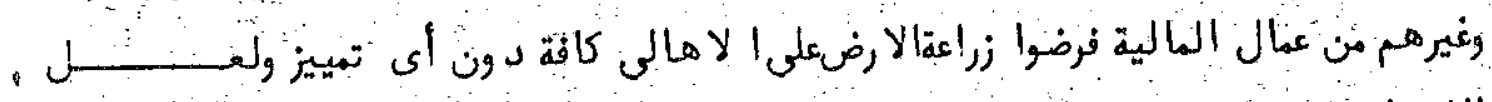

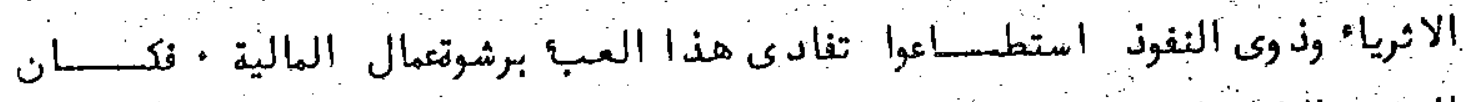

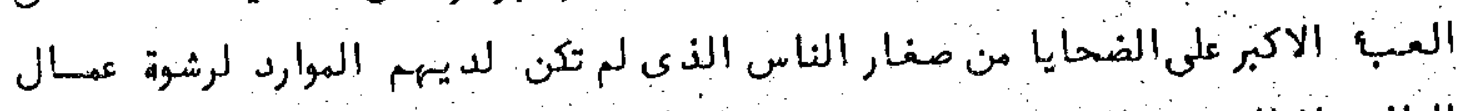

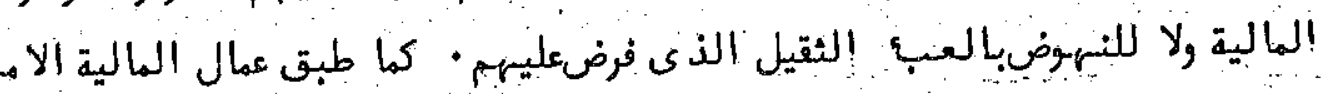

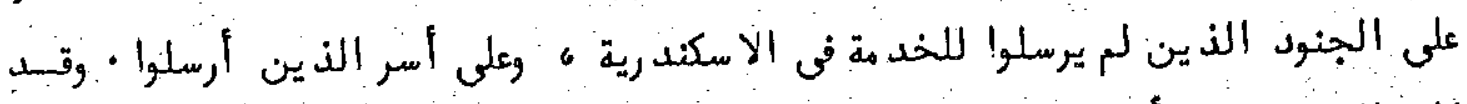

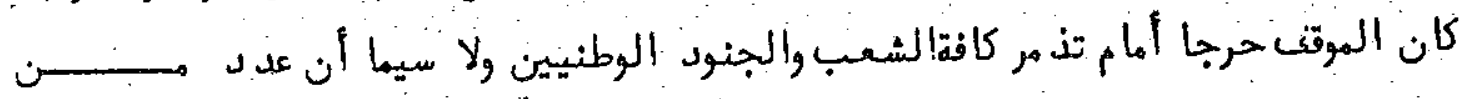

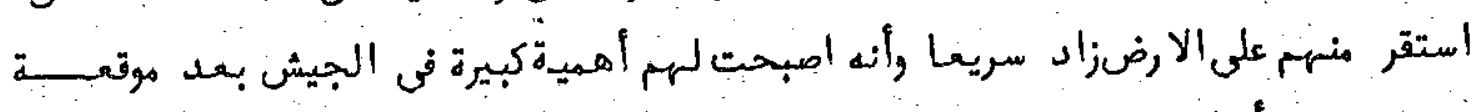

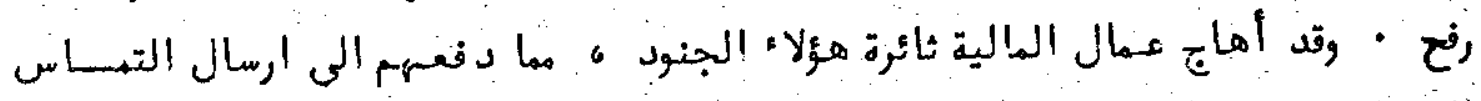

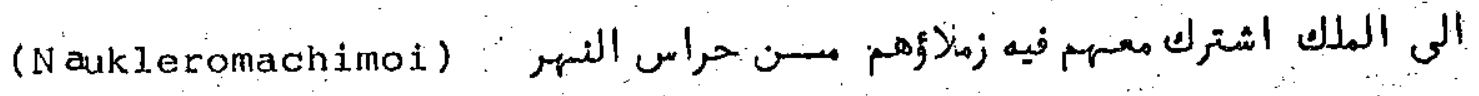

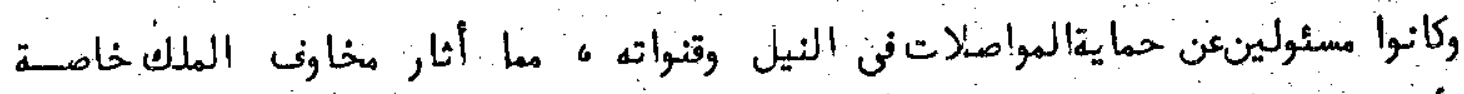

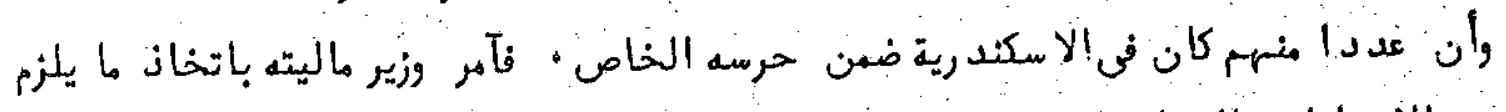

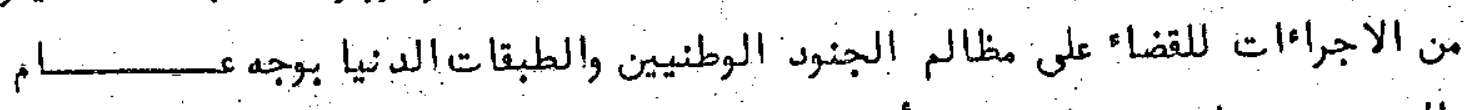

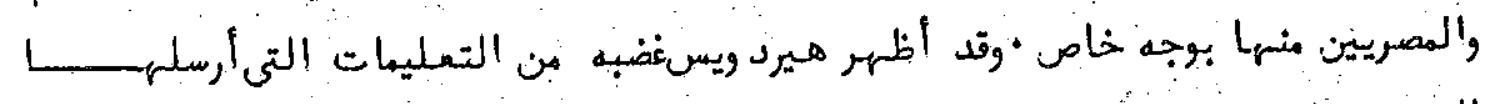

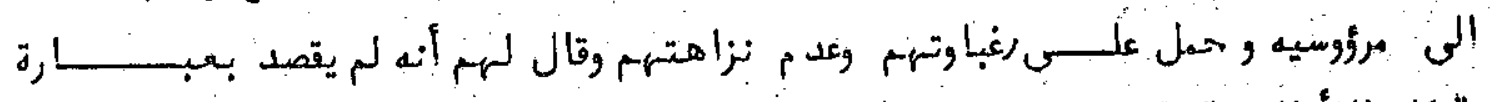

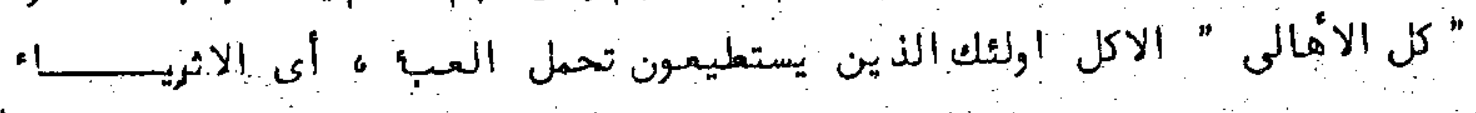

(1) M. Rostovtzeff, Soc. and Ec., PP. 717-20.

(2) U.P.Z., 110, 11, 91-94.

/ (3) U.P.Z., 110, 1.99. 


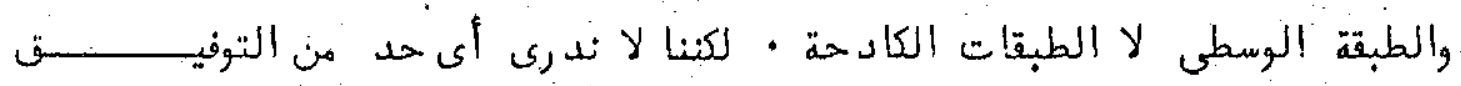

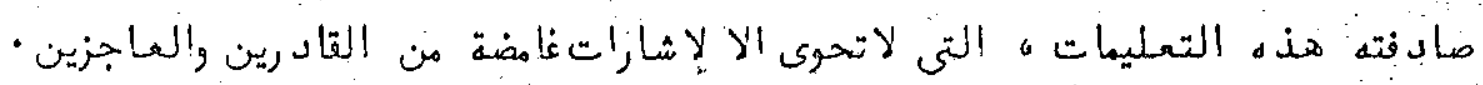

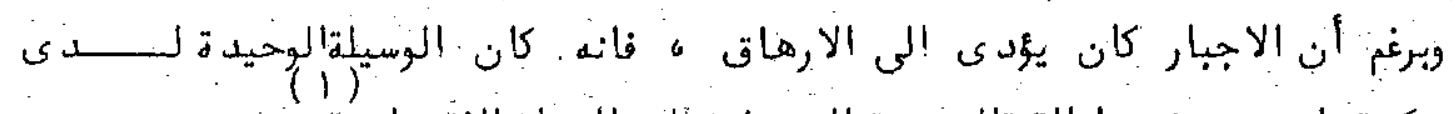

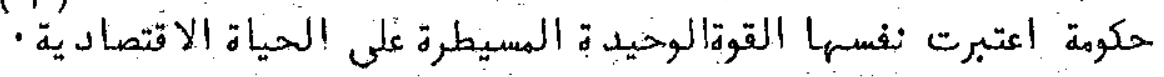

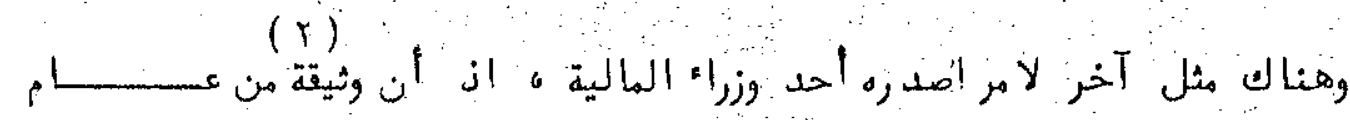

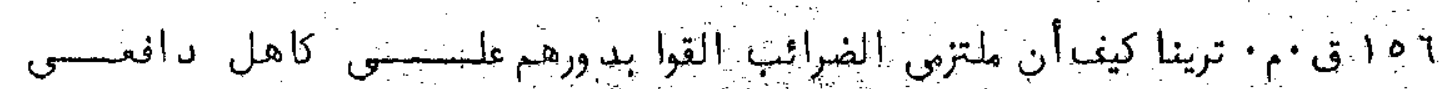

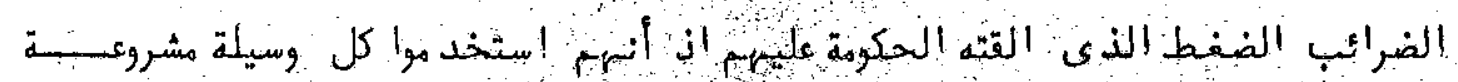

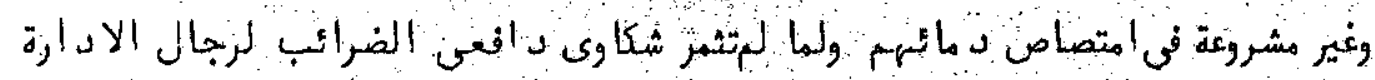

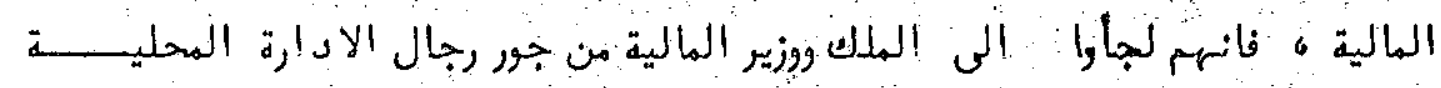

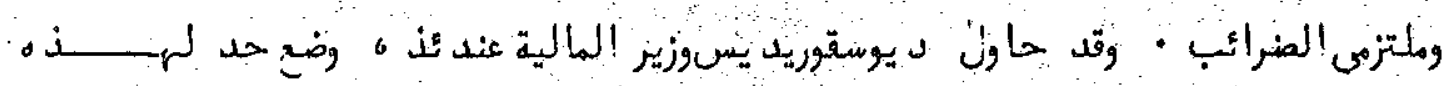

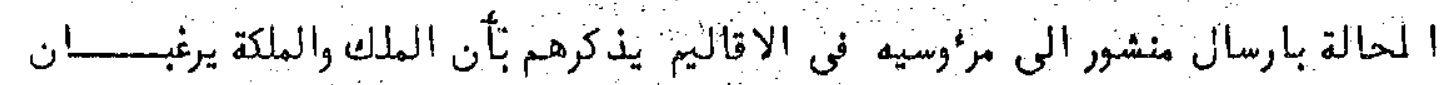

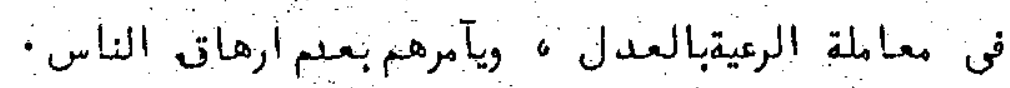

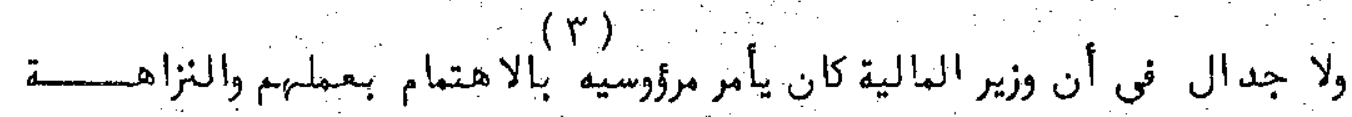

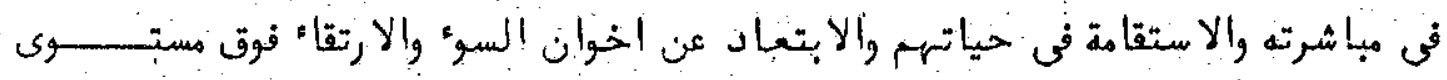

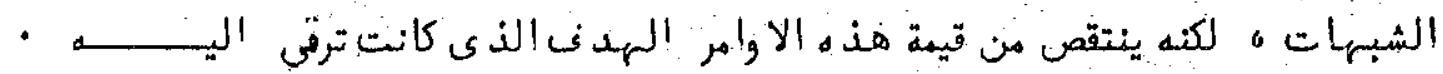

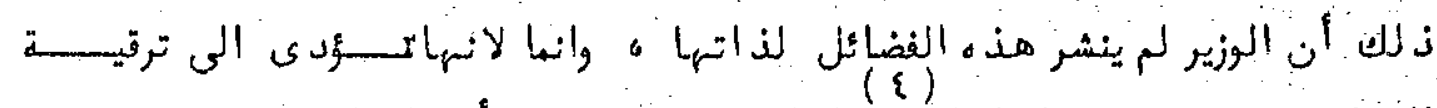

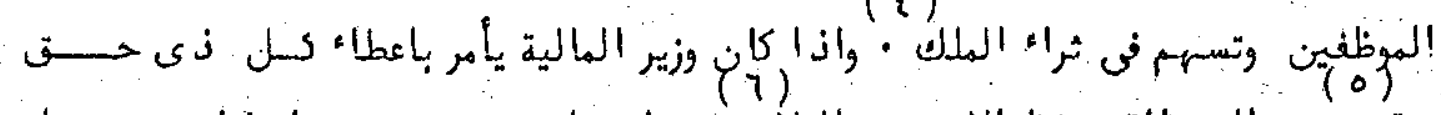

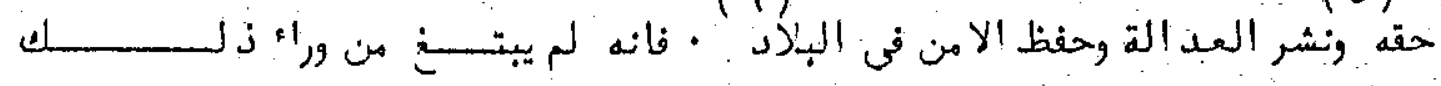

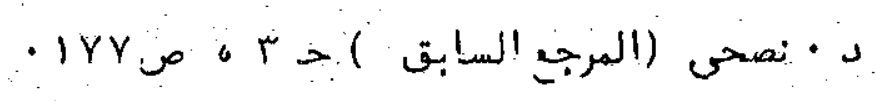

(2) U.P.Z., 113

(3) P. Tebt., 703, 11. 272 ff.

(4) C. Préaux, Op. cit., P.565

; (5) Cf. U.P.Z., 110

(6) P.Tebt., 703, 11. 40-49; U.P.Z., 113 


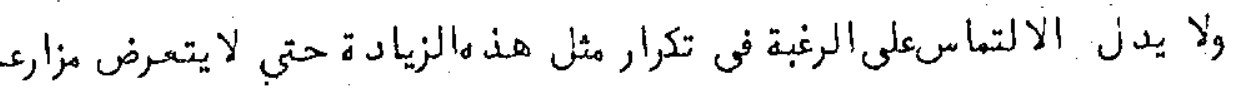

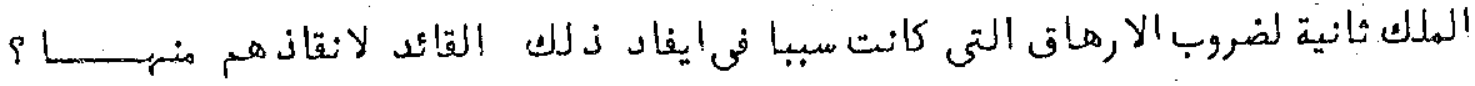

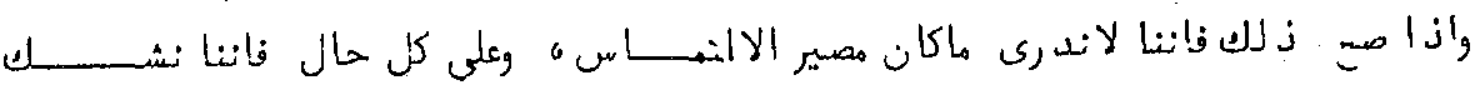

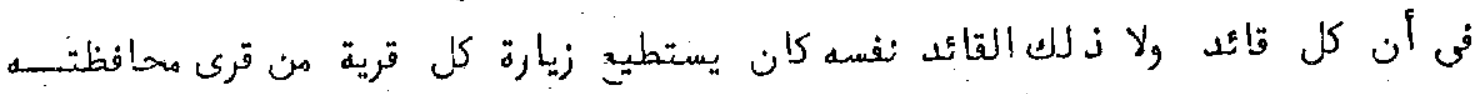

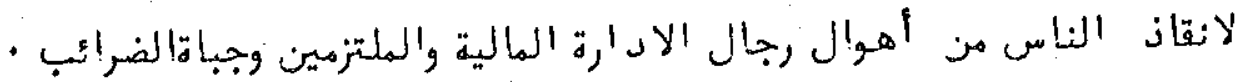

ح

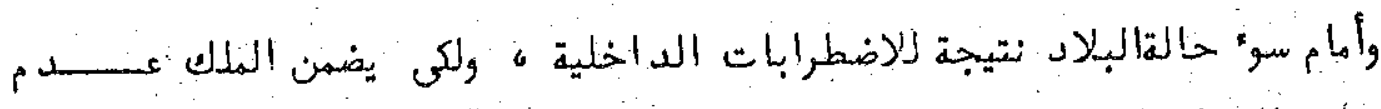

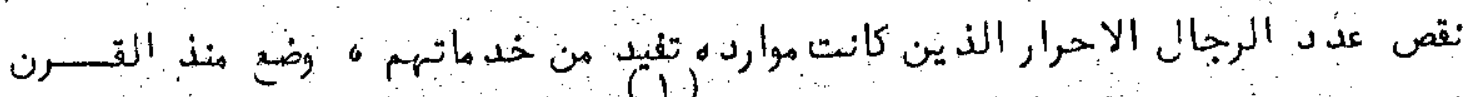

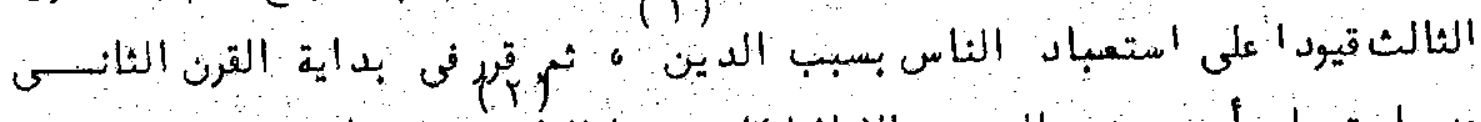

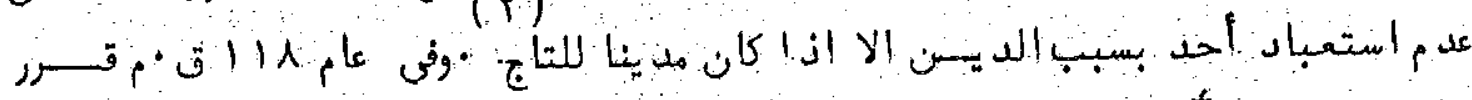

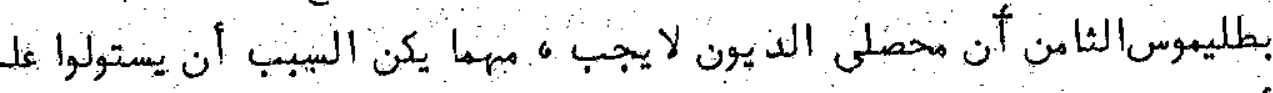

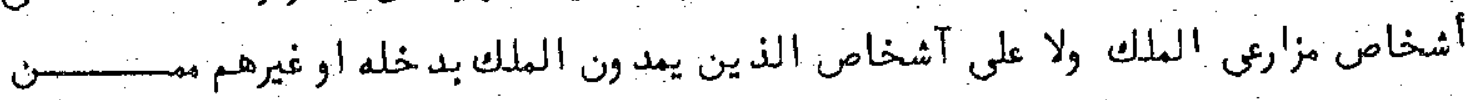

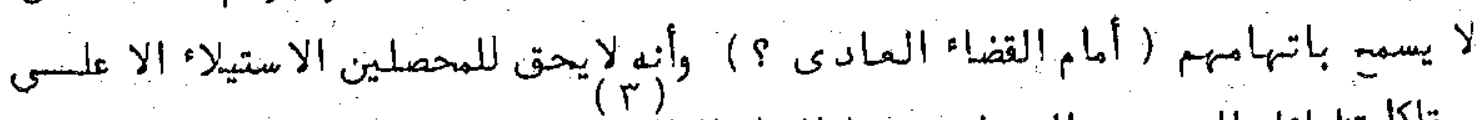

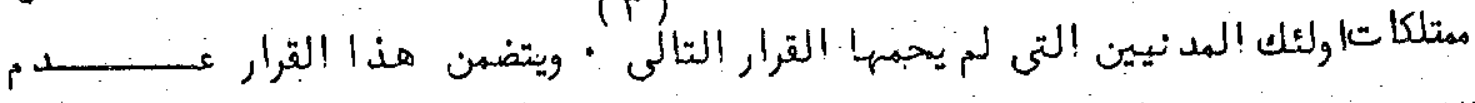

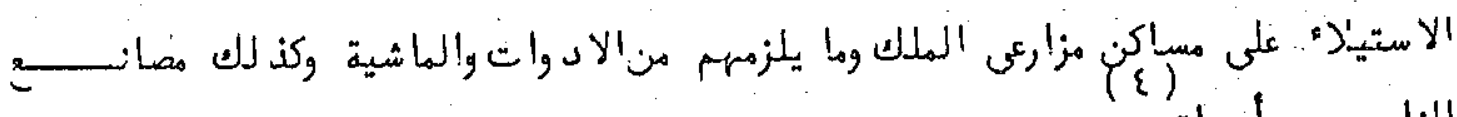

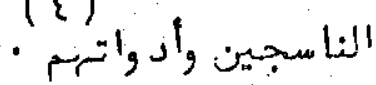

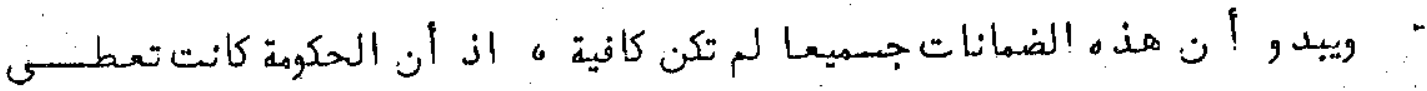

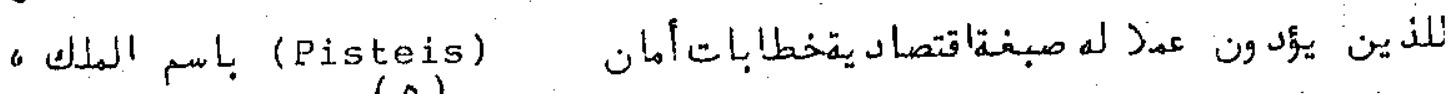

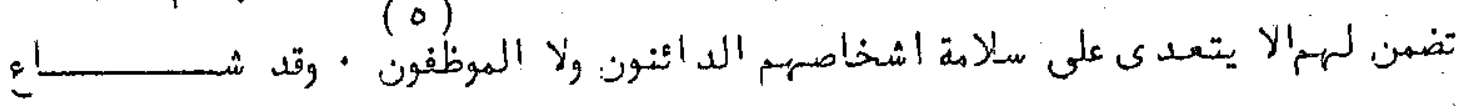

(1) P. Hibeh, 88; 89; B.G.U., 1273-1278; P. Cairo-Zenon, 59340 .

(2) C. Preaux, Op.Cit., P. 541.

(3) P. Tebt., 5, 11, 221-230; Cf., C. Préaux Op.Cit., 542.

i (4) P. Tebt., 5, 11, 231-247.

(5) C. Preaux, Op.Cit., PP.543 ff. 


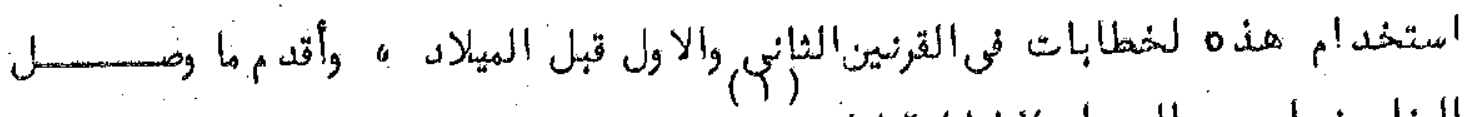

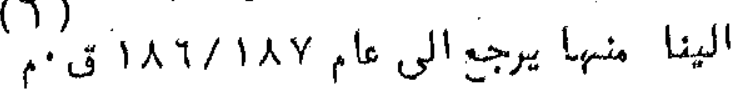

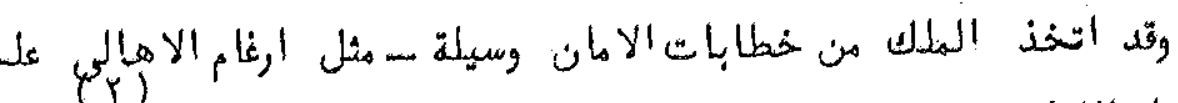

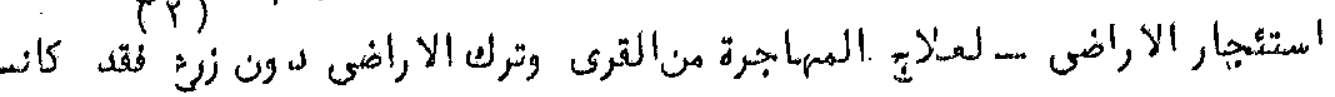

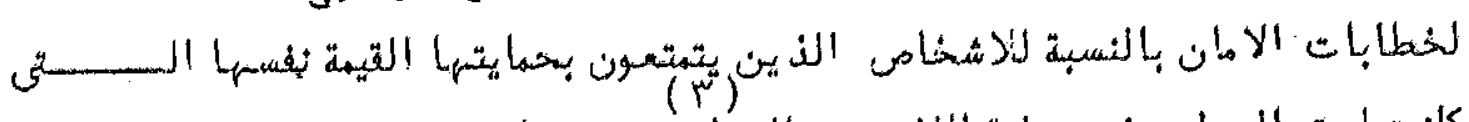

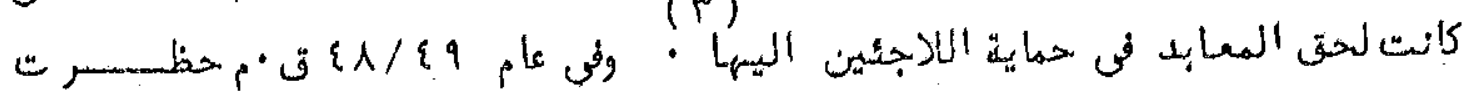

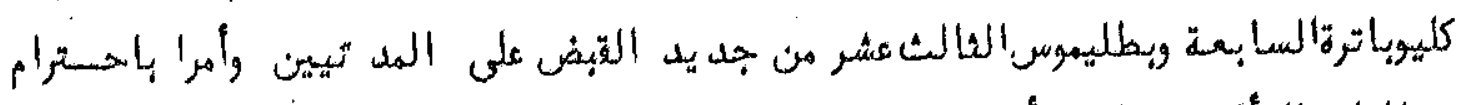

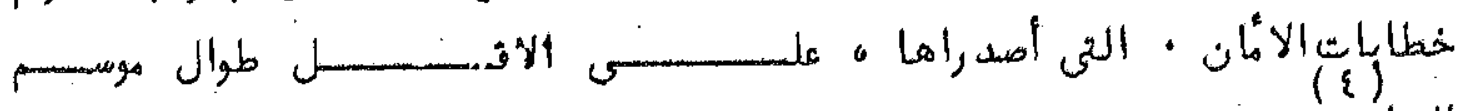

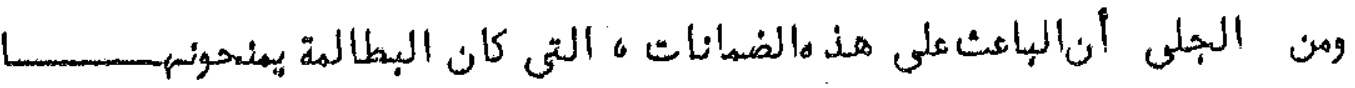

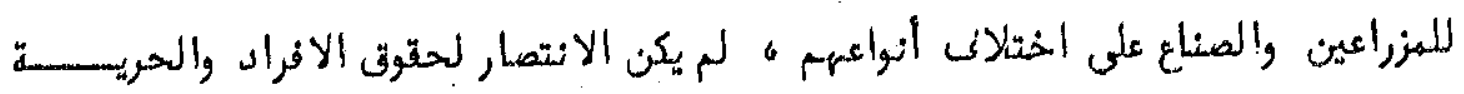

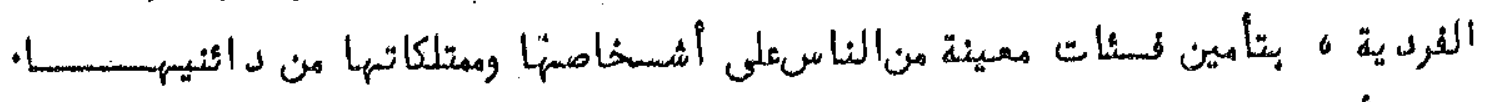

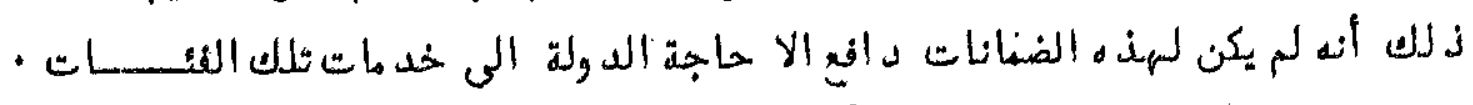

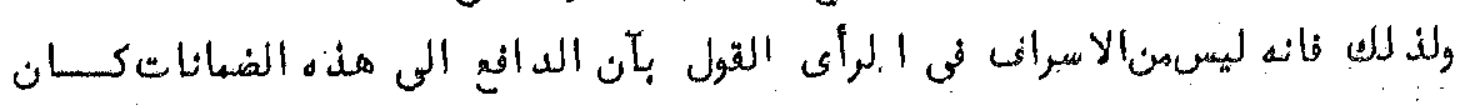

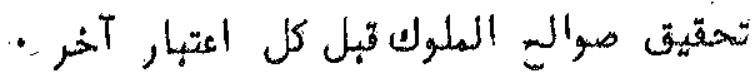

\section{ثانيا : قرإبات عفور الملوك البطالهة}

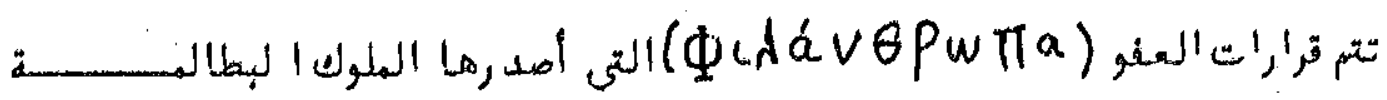

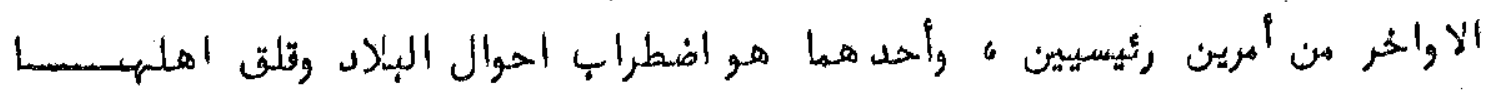

(1) P. Tebt., 741 (187/6 B.C), U.P.Z., 124 (175/4 or 165/4); B.G.U., 1810,(52/1 B.C): 1811 (48/7).

(2) C. Préaux Op. Cit., P. 544

$$
\text { • }
$$

(4) B.G.U., 1812. 


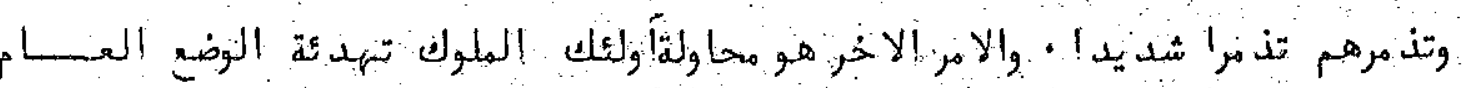

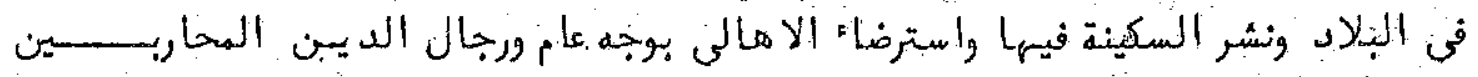

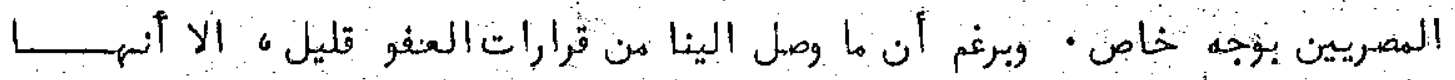

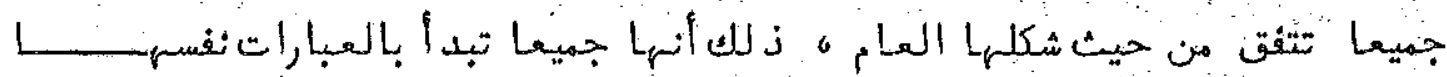

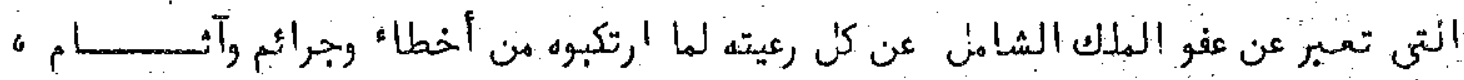

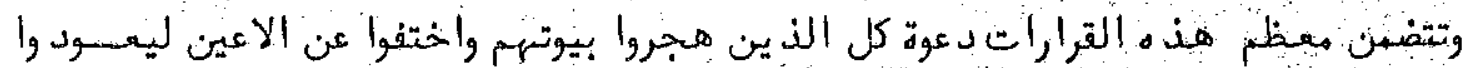

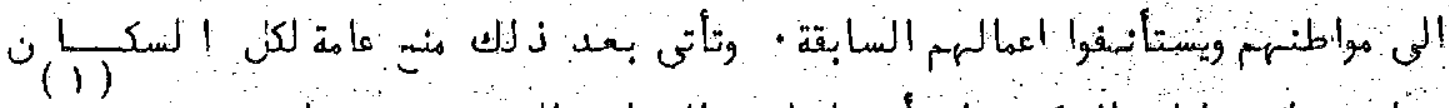

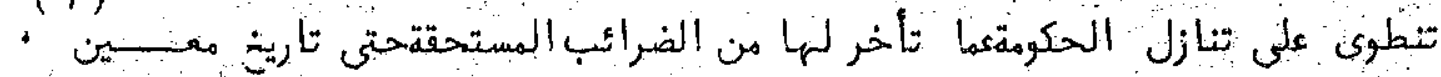

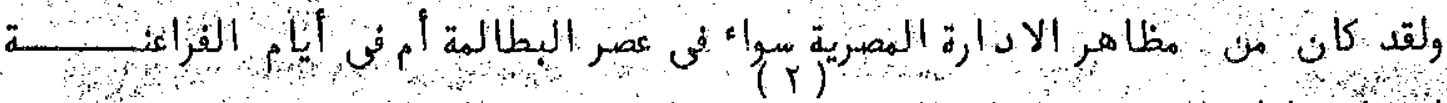

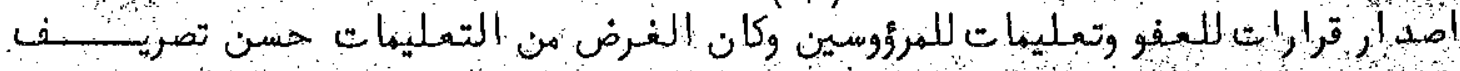

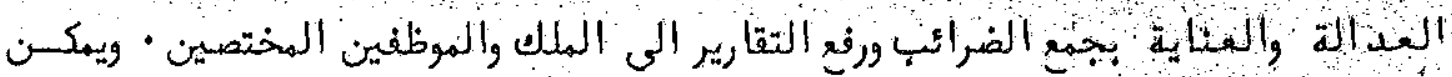

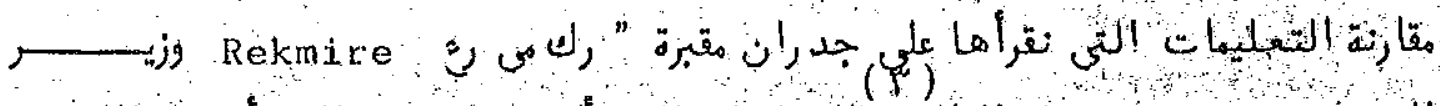

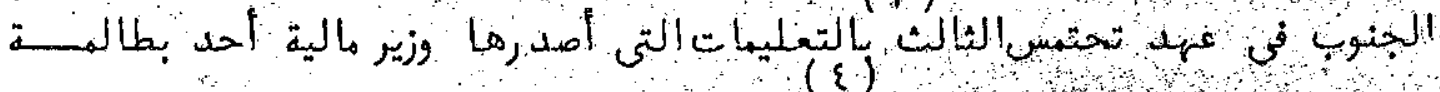

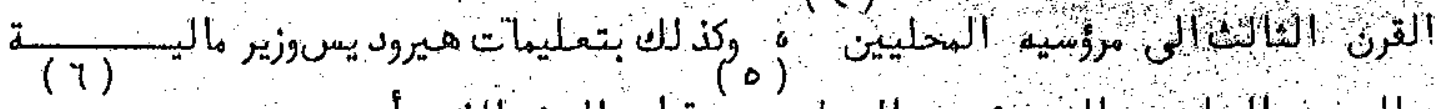

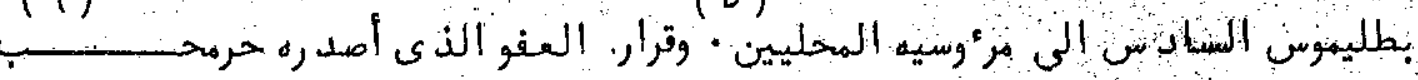

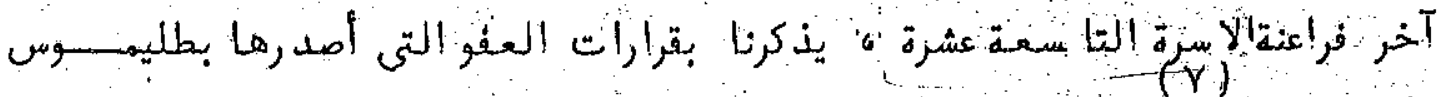

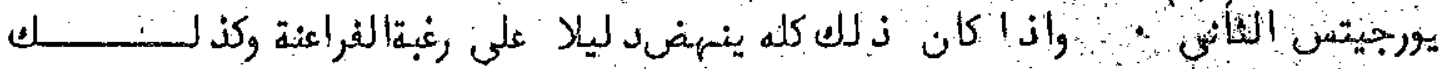

(2) Cf, P. Teb., I, P. 19.

(2) Welles, The Ptol. Adm. in Eg., J. Jur. Pap. III, 1949, PP. 32 EE.

(3) Breasted, Ancient Records, I, PP. 266. 95.

(4) P. Tebt., 703

(5) U.P.Z., 110

(6) Breasted, Op. Cit., PP. 22-33, nos.45-67.

(7) P. Tebt., I, 5, PP. 17-7. 


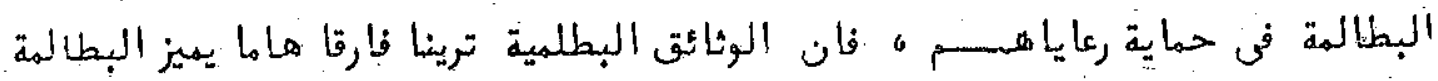

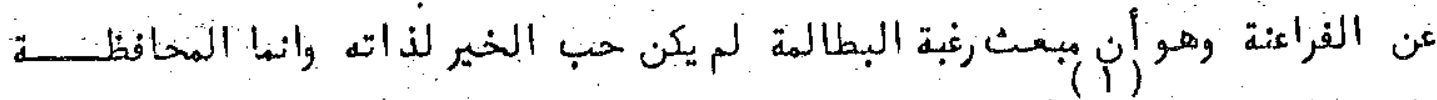

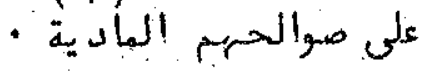

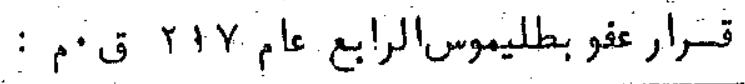

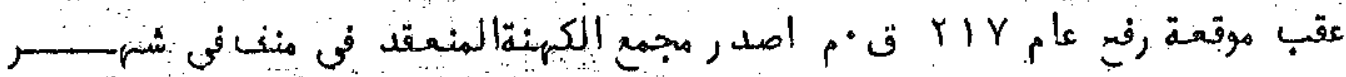

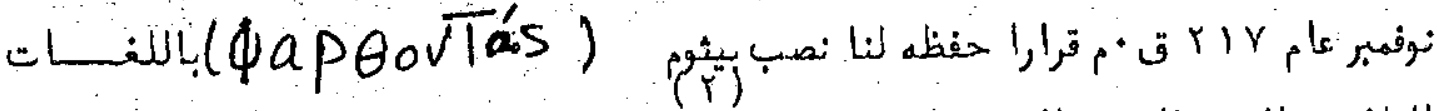

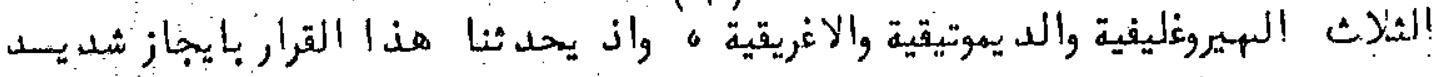

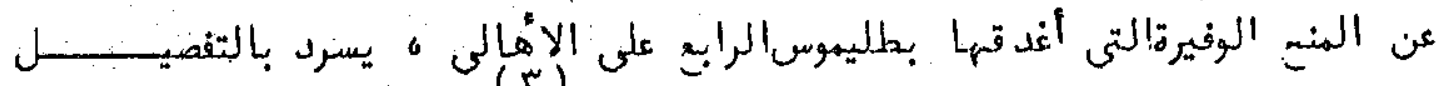

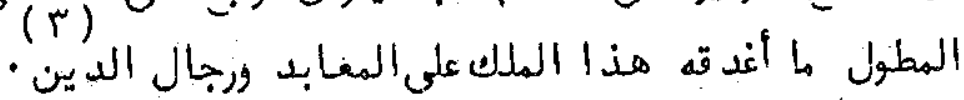

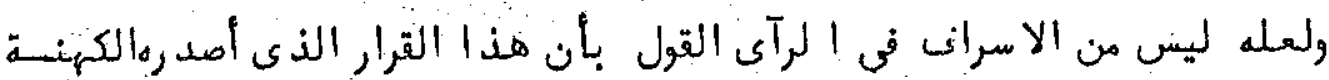

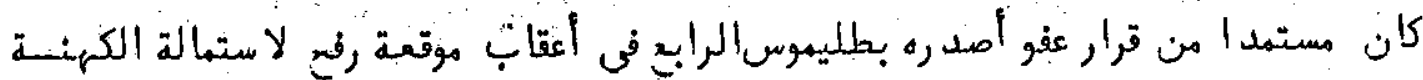

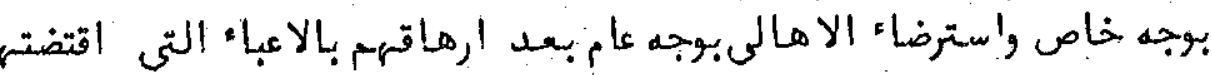

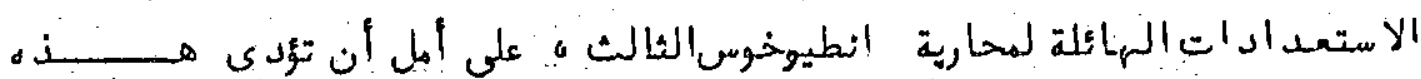

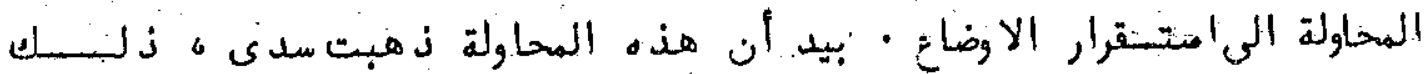

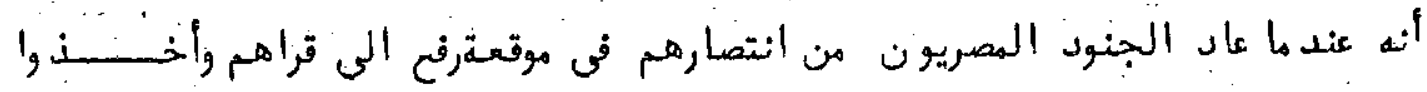

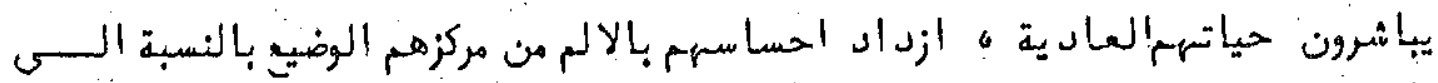

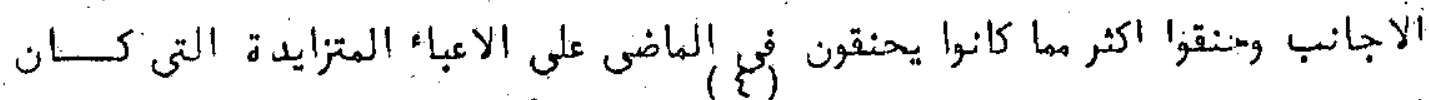

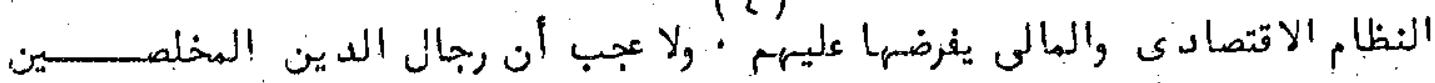

(1) P.Tebt, , I, 5, P $\overline{17-7}$

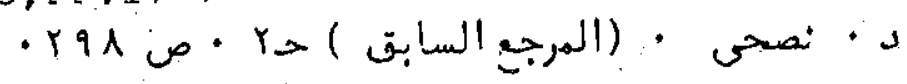

(2) H. Gauthier, H. Sottas, Un Decret Trillingue en I'Hanneur de Ptolemée IV, Service des Antiquites de I'Egypte, Cairo 1925; W. Spiegelberg, Beitrage Zur Erklarung des neuen dreisprachigen Priesterdekretes Zu Ehren des Ptolemaios Philopator, Munchen, 1925, PP. $1-30$

(3) Cf. E. Bevan, Op.Cit., PP. 389-391.

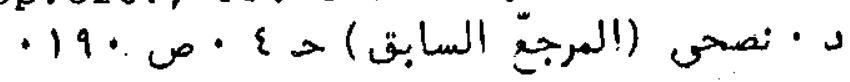




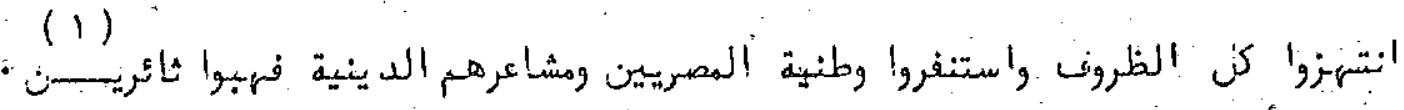

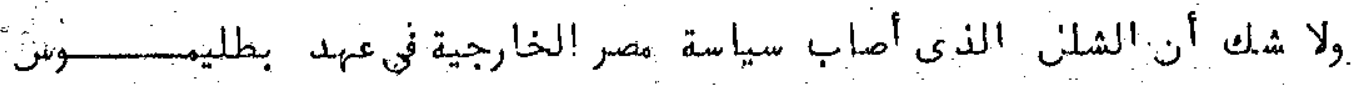

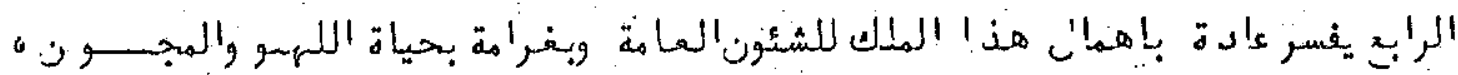

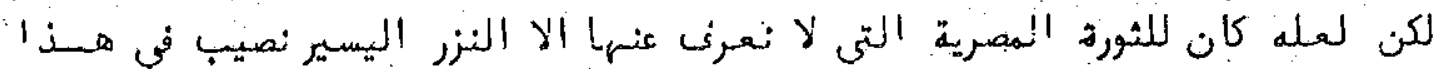

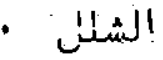

\section{قرا عفو بطليفوسن الخامس عام}

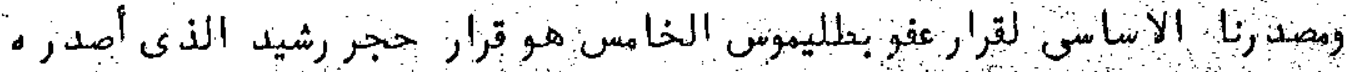

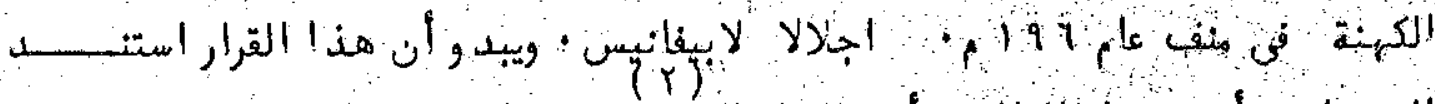

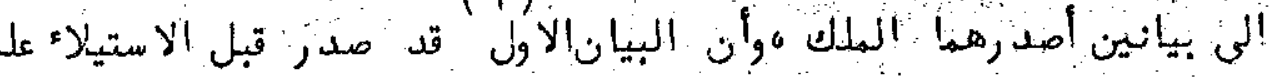

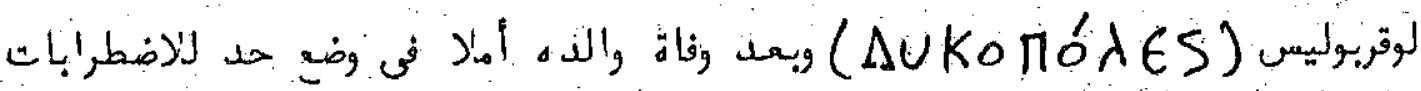

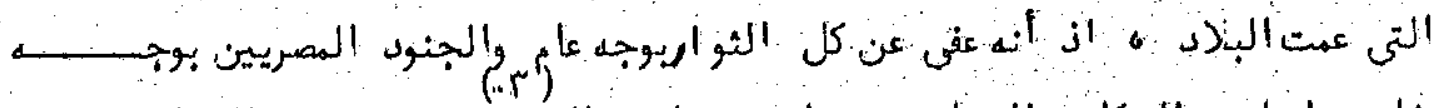

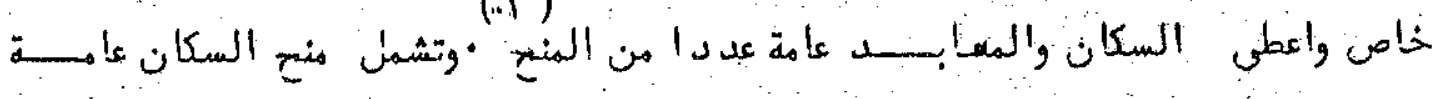

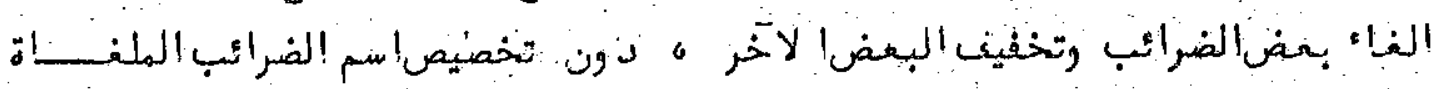

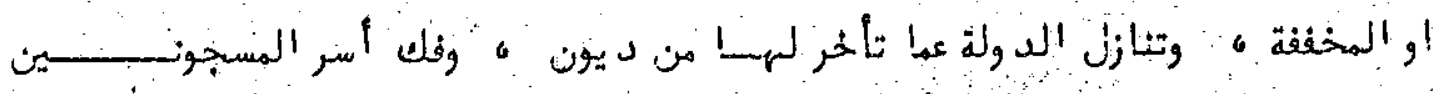

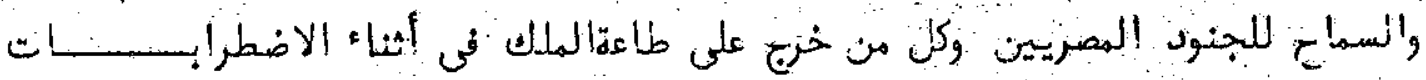

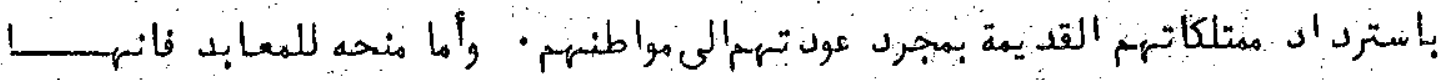

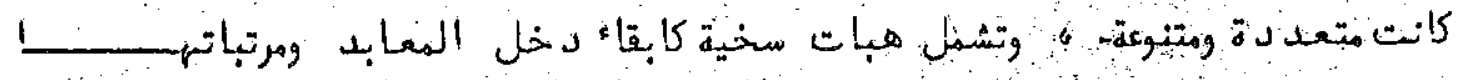

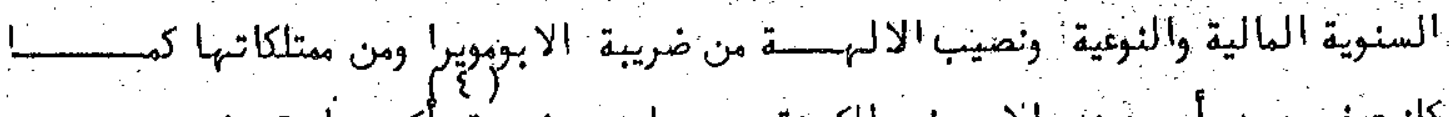

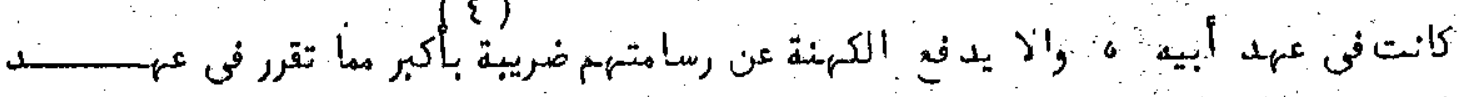

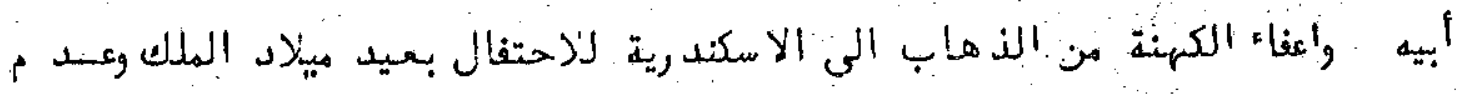

(1) M. Rostortzeff. Soc. and Ec., PP. 709-10

(2)0. G.I.S., 90, $11.10 \mathrm{ff}$.

(3) M. Rostortzeff, Soc, and Ec., P. 713.

:

w. Otto, Priester Und Templ1é, I. PP. 211-12. 


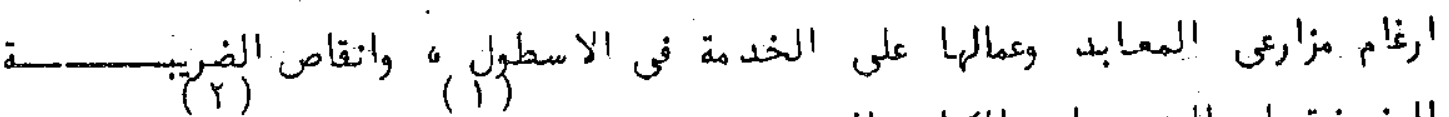

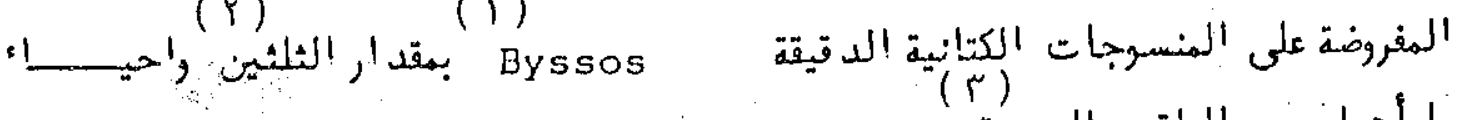

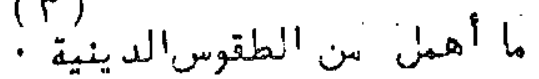

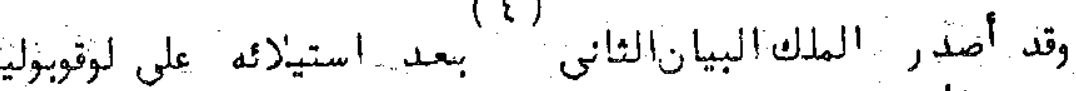

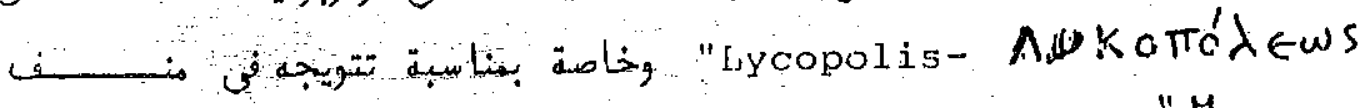

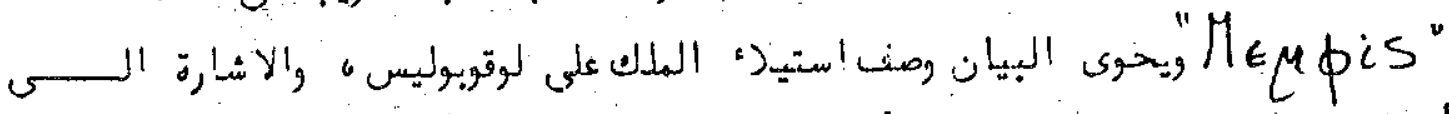

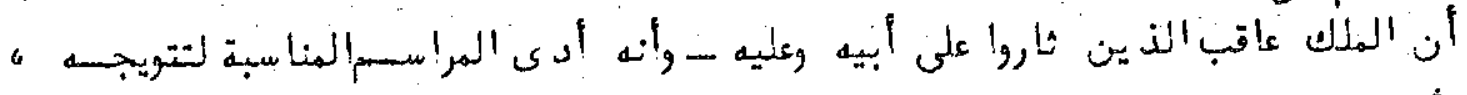

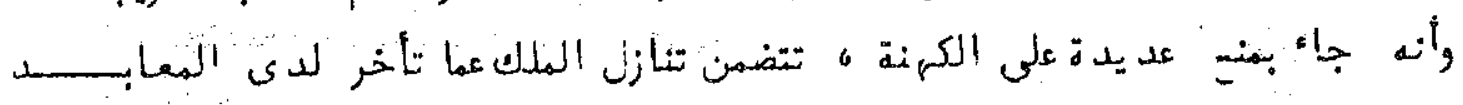

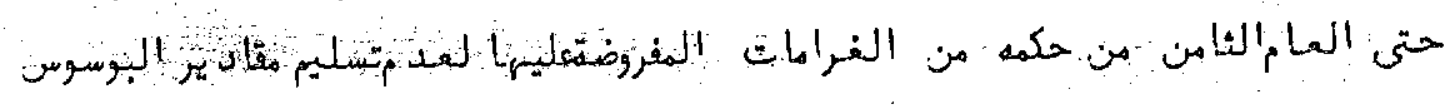

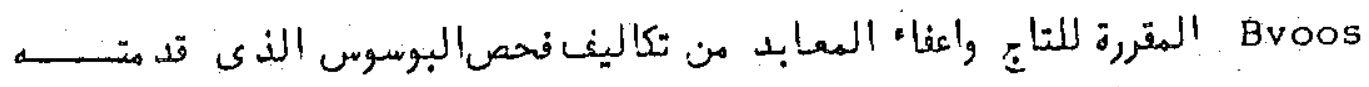

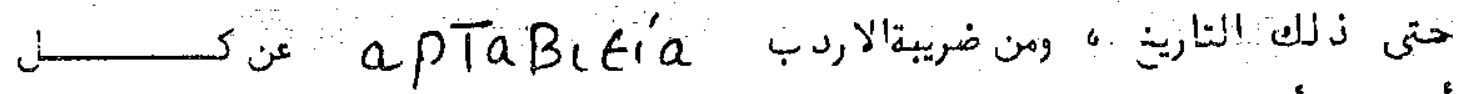

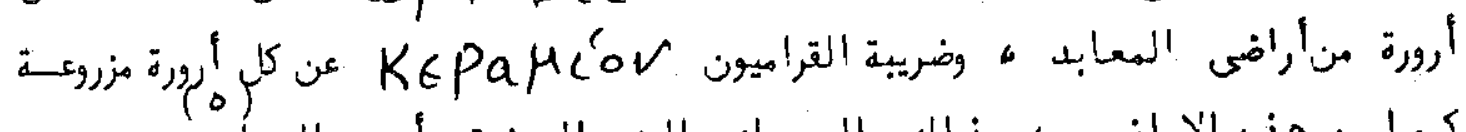

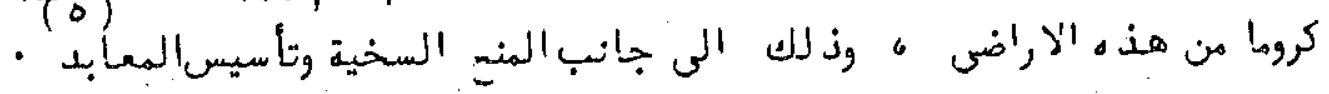

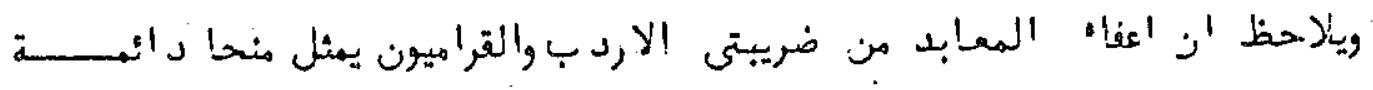

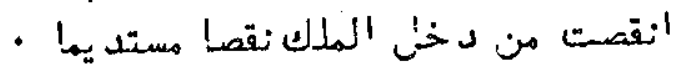

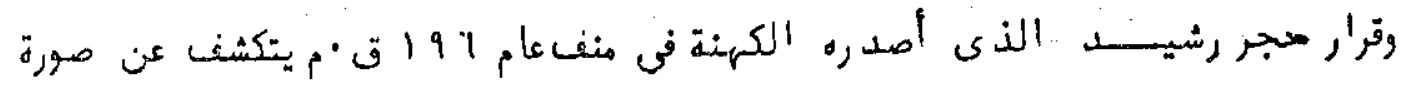

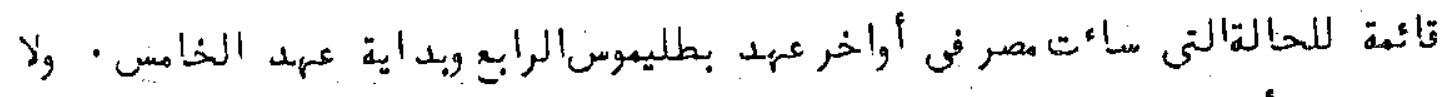

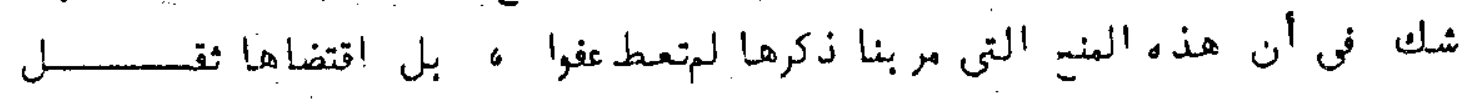

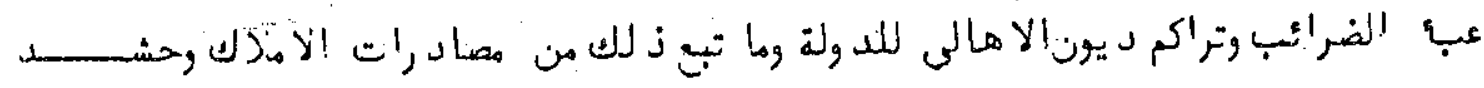

(1) Cf., R.L., Cols., 98, 899

(2) E. Bevan, Op.Cit., P. 265.

(3) E. Bevan, Ibid., 265.

(4) O.G. I.S., $90.11,20 \mathrm{ff}$.

(5) E. Bevan; Op. Cit., 265-6. 


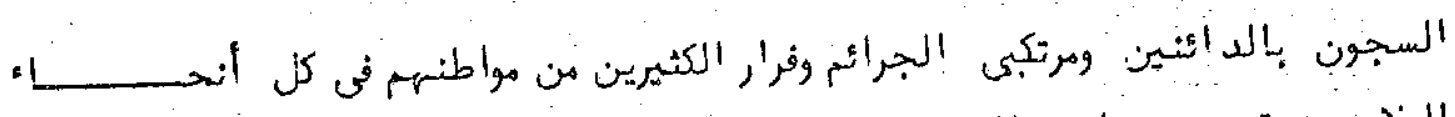

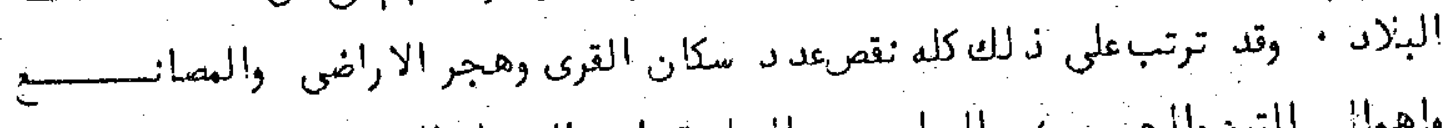

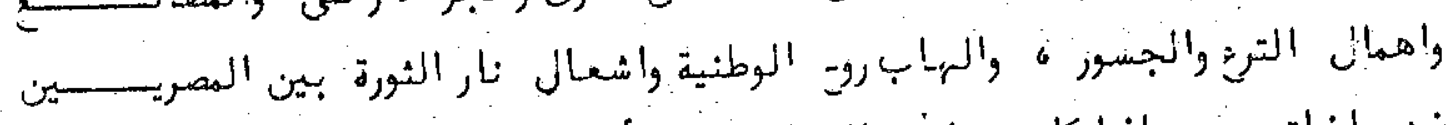

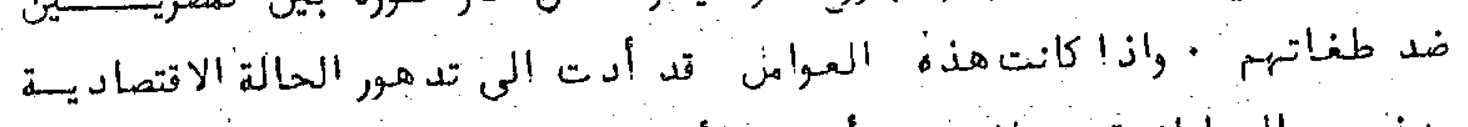

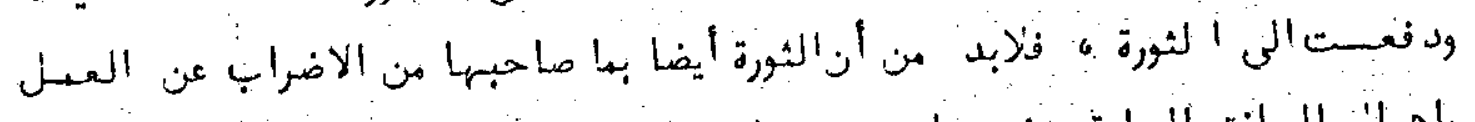

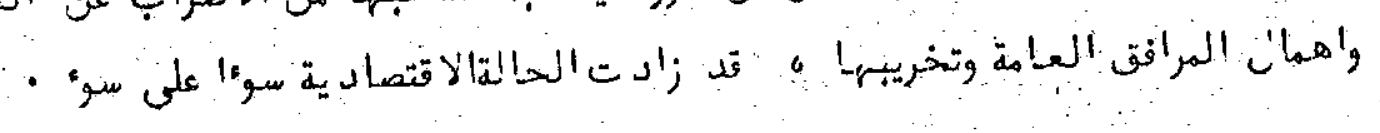

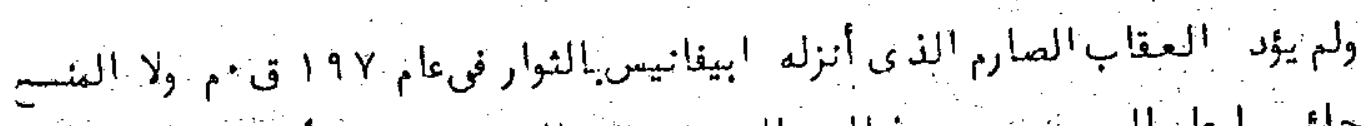

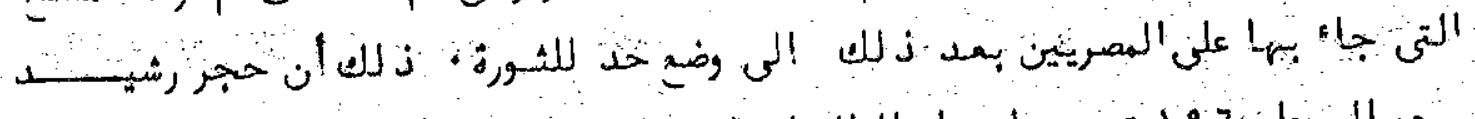

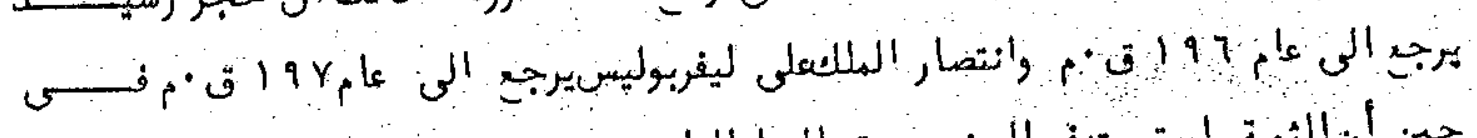

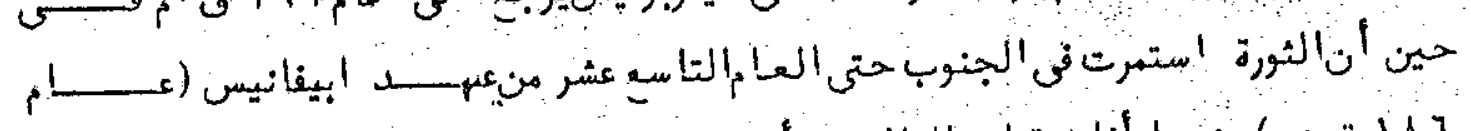

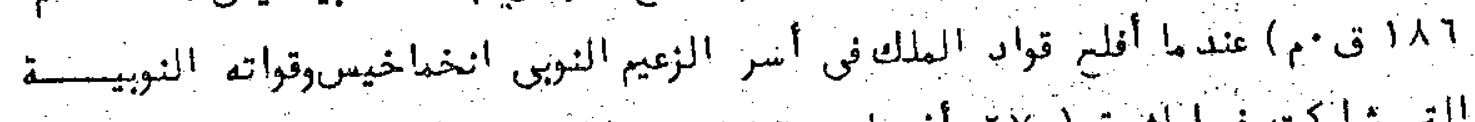

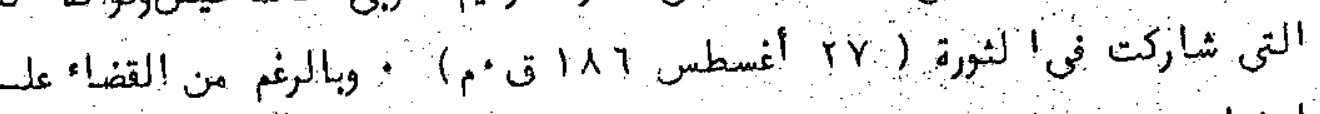

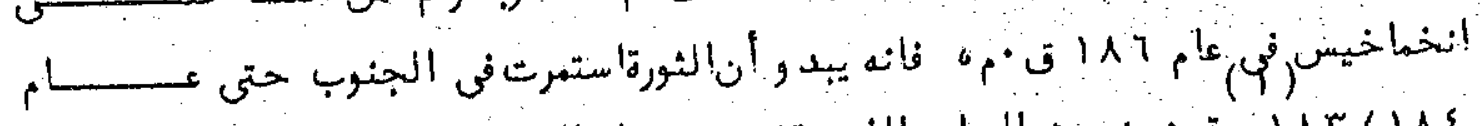

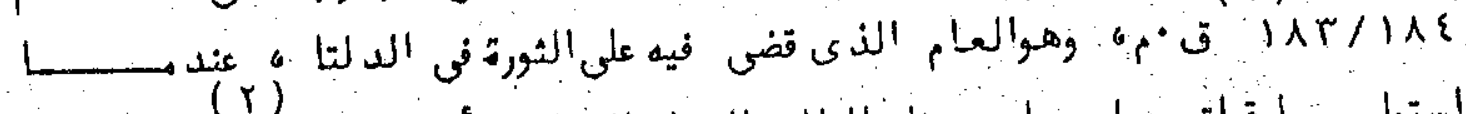

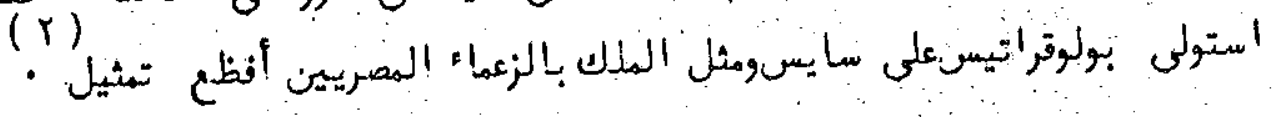

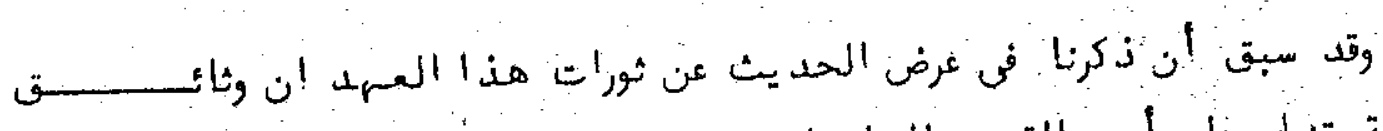

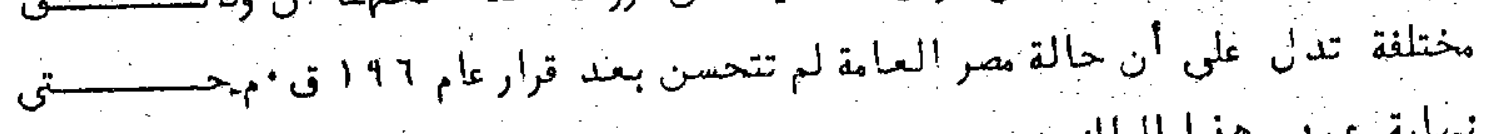

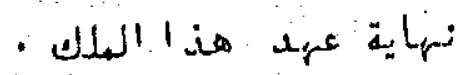

(r)

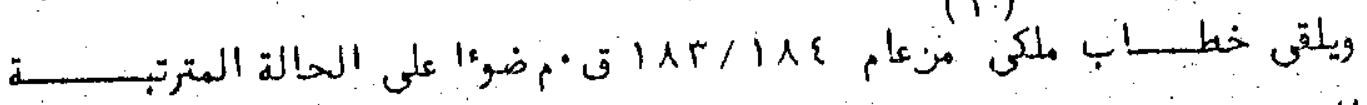

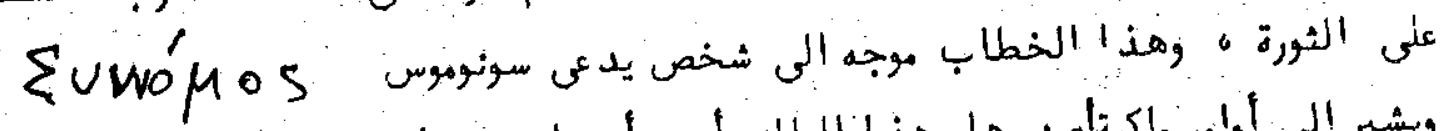

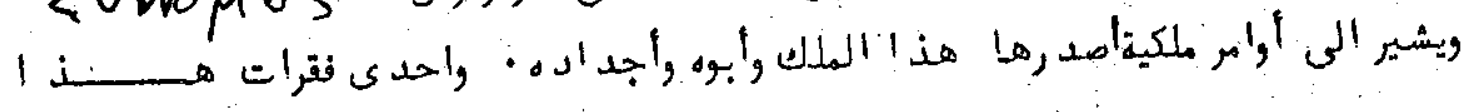

i (1) M. Rostotzeff, Soc. and Ec., PP. 715-6.

(2) Polyb., XXII, 17,3.

(3) Sammelbuch, 5675; Cf. P. Tebt., 703, Intr. P. 69;

C. Préaux, Econ. Lag., P. 522 . 


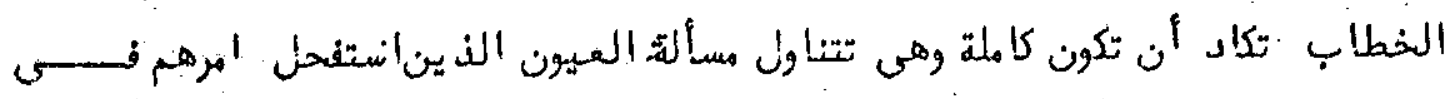

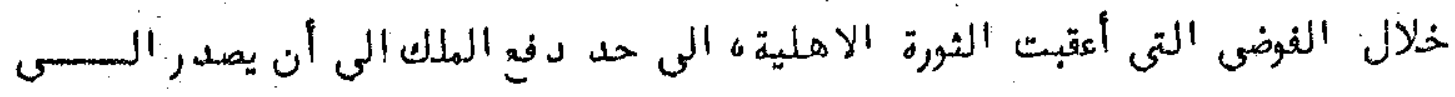

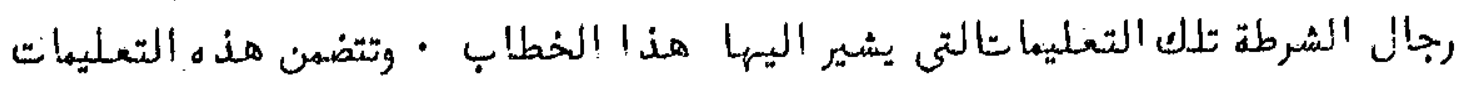

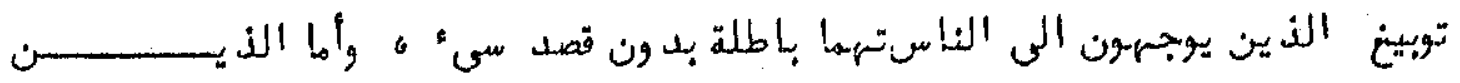

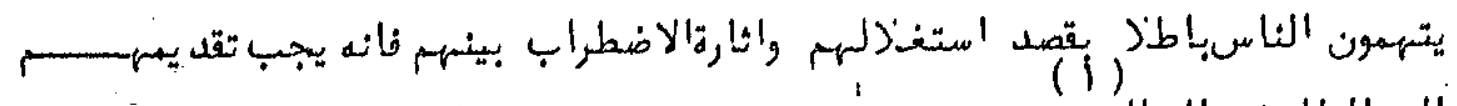

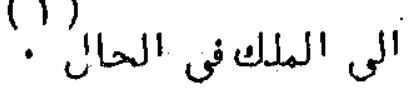

(r)

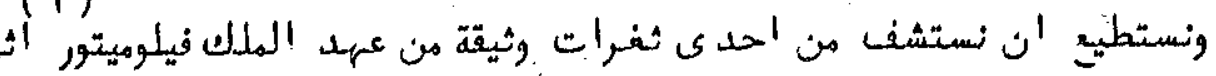

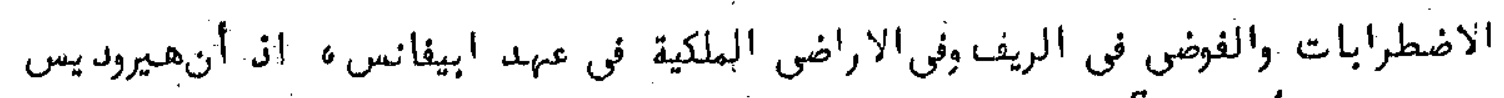

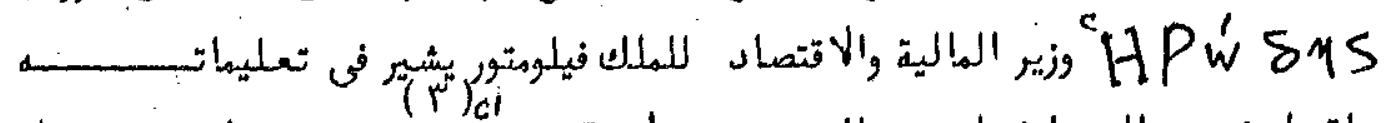

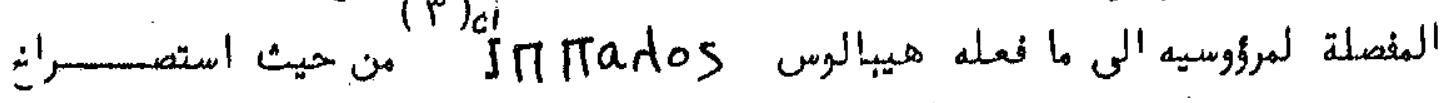

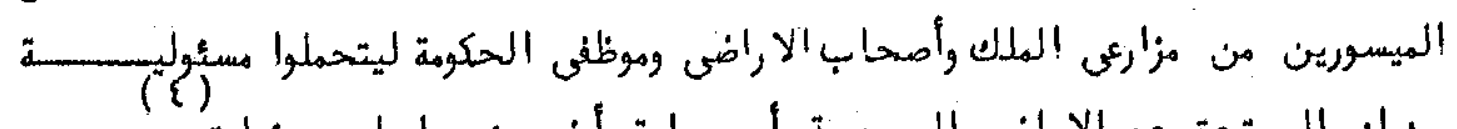

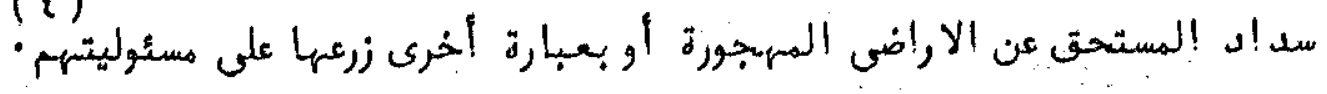

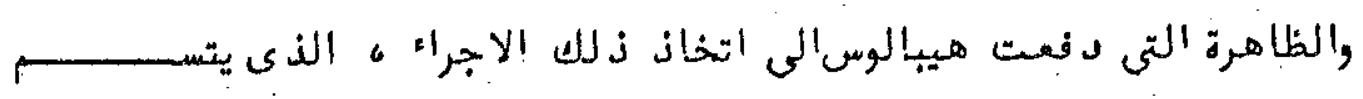

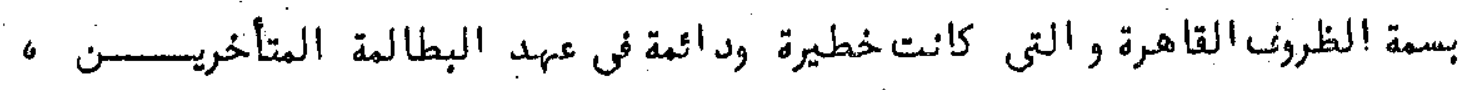

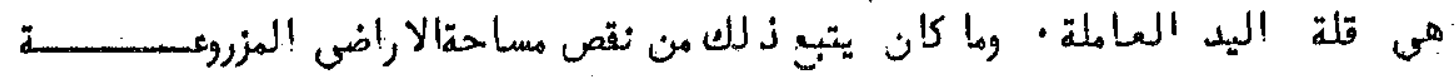

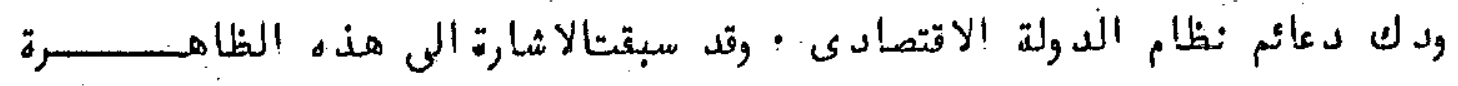

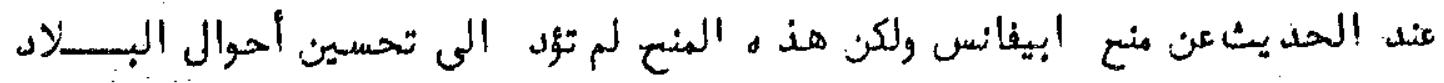

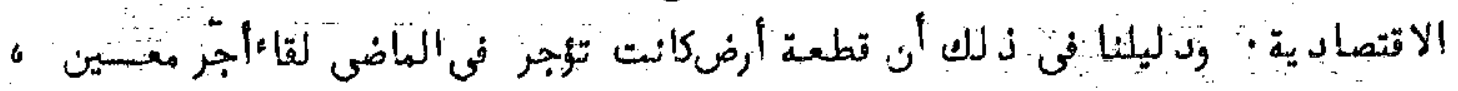

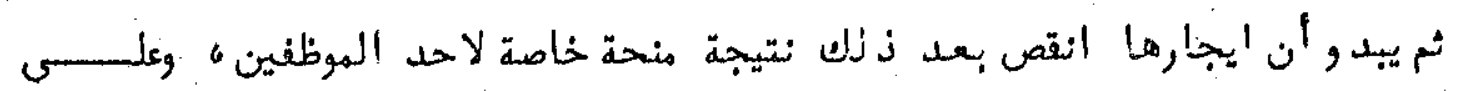

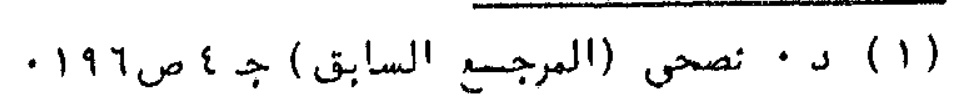

(2) U.P.Z., 110, PP. 473-496.

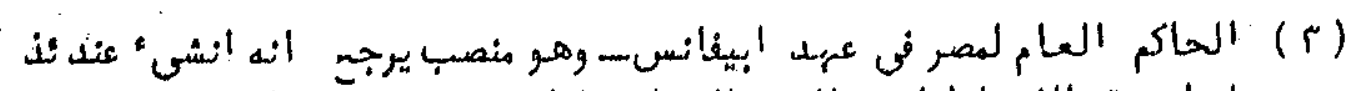
i

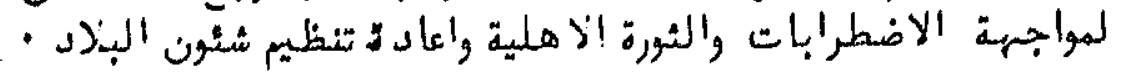

(4) M. Rostovtzeff Soc. and Ec., pp. 717-18. 


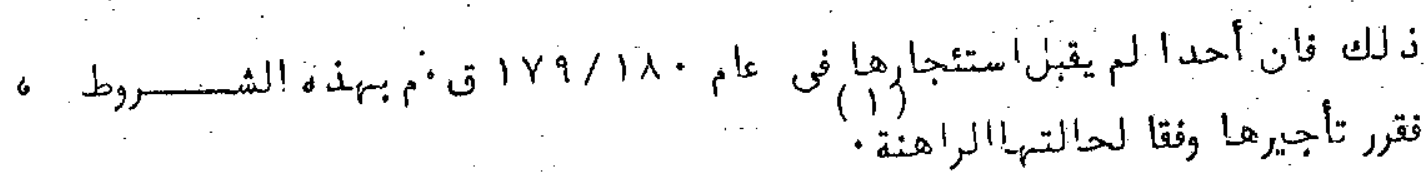

وفي ضيعةابولونيوس' نسا بقة ه أصبحت توجد مساحات كبيرة من الاراض

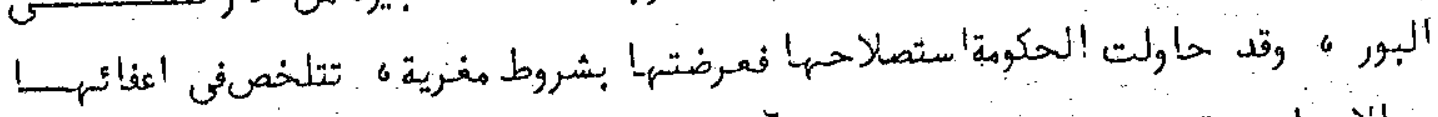

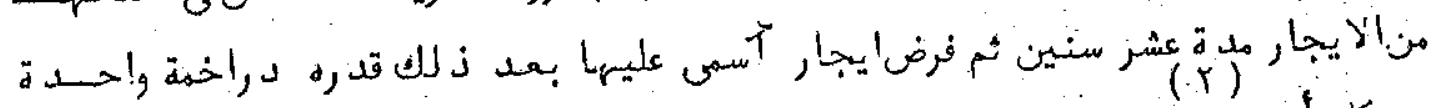
كن كل أرورة

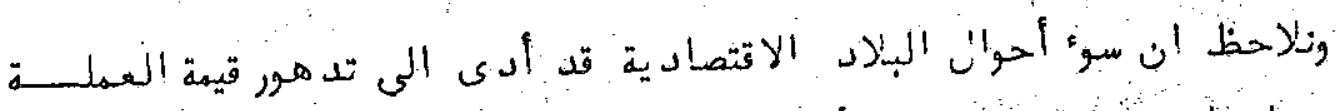

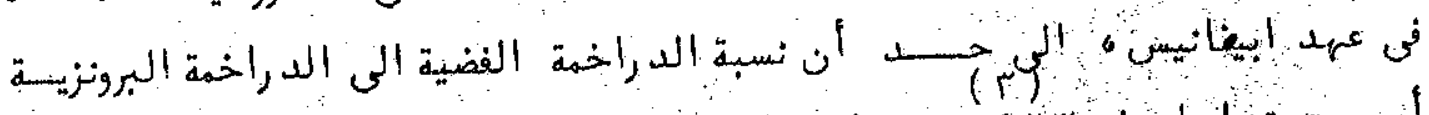

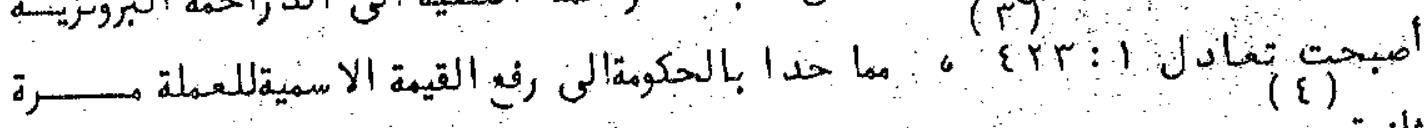
ثانية

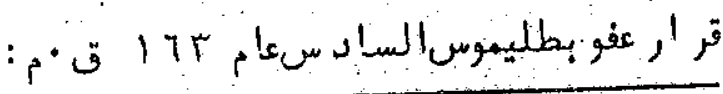

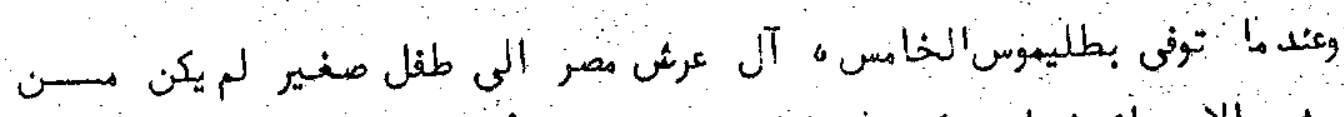

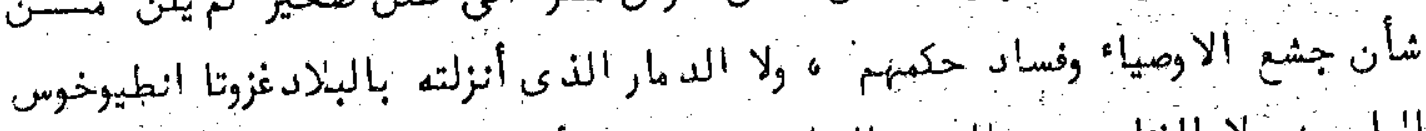

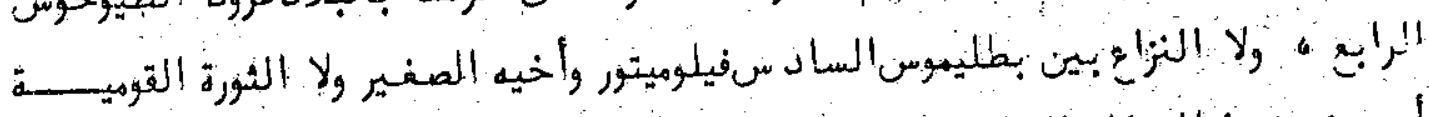

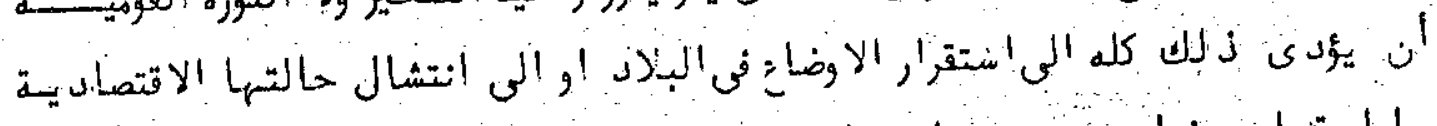

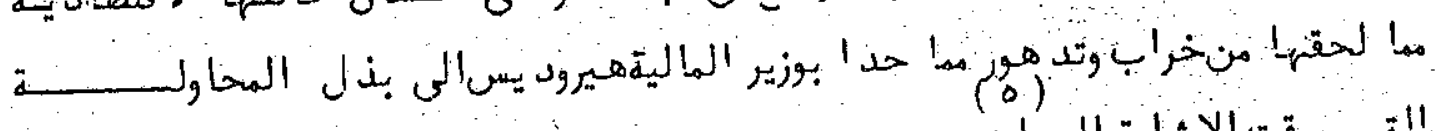

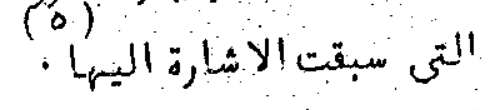

(1) P. Tebt., 82911,19 f. .

(2) P. Tebt., 918 .

(3) P. Mich., III, 182.

(4) M. Rostovtzeff, Soc, and Ec., Chap. V. Note No. 131;

Cf. T. Reekinans, Ptol; Copper., P. 65.

(5) U.P.Z., 110, PP. 473-496. 


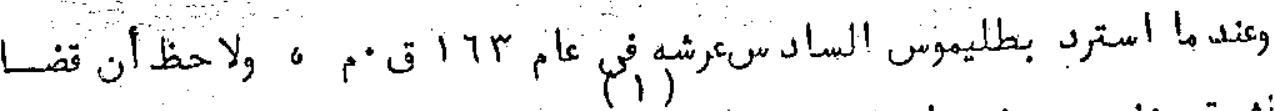

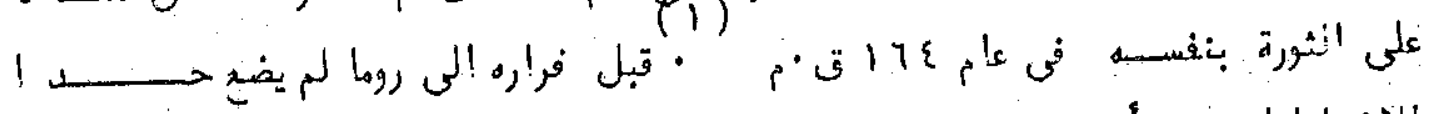

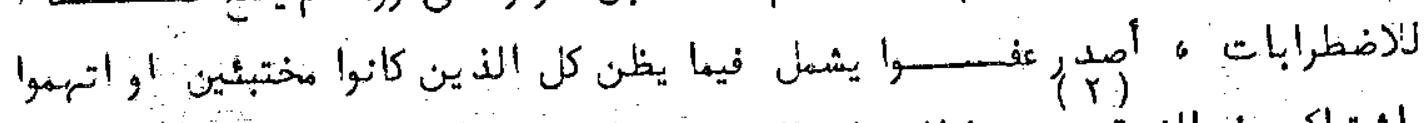

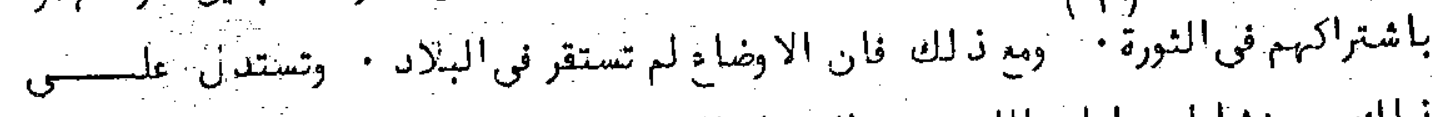

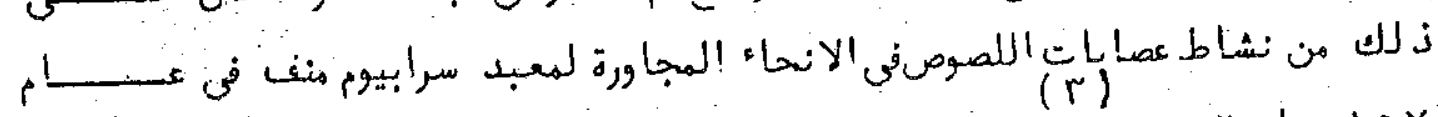

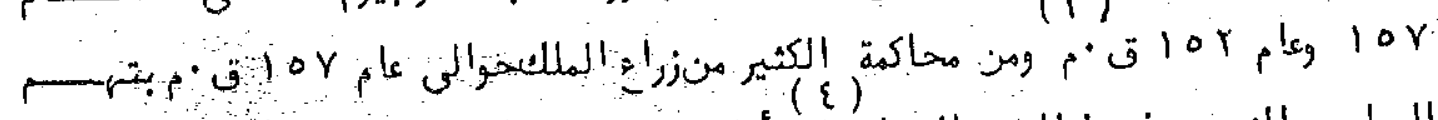

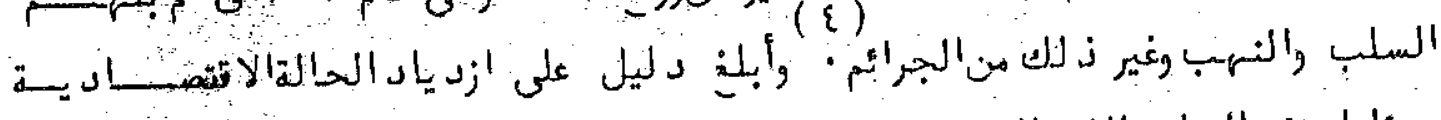

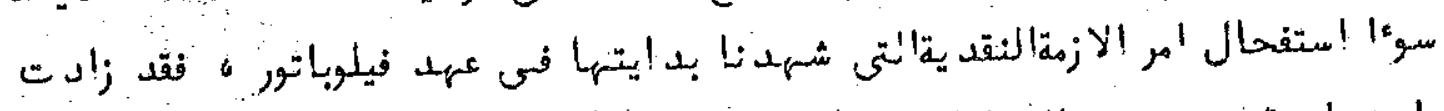

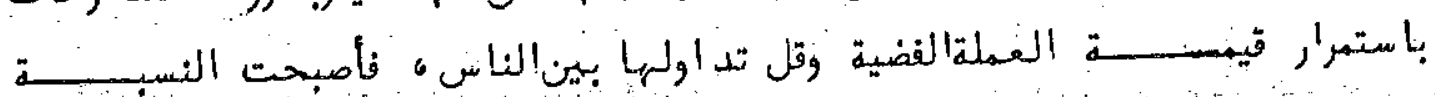

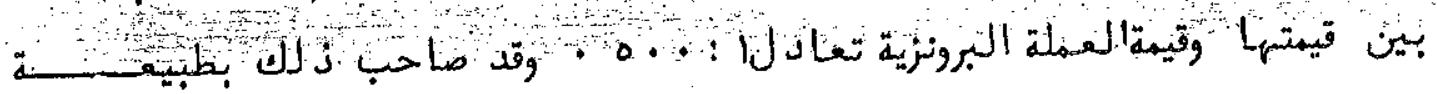

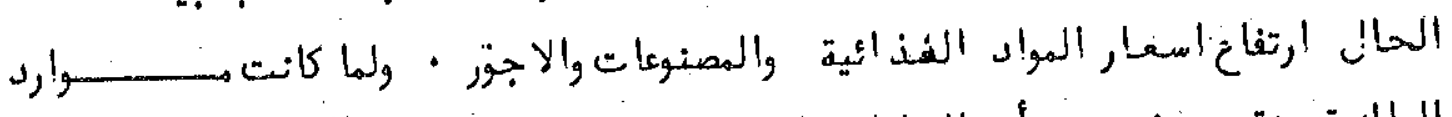

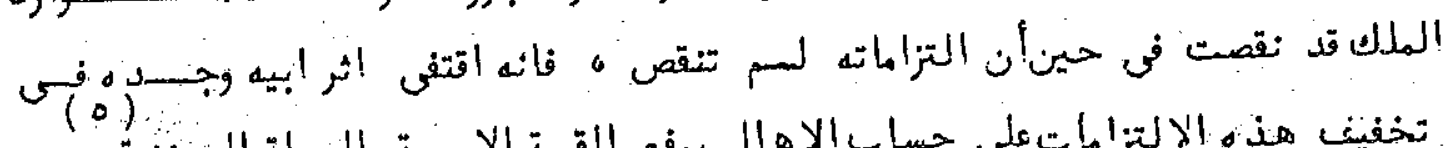

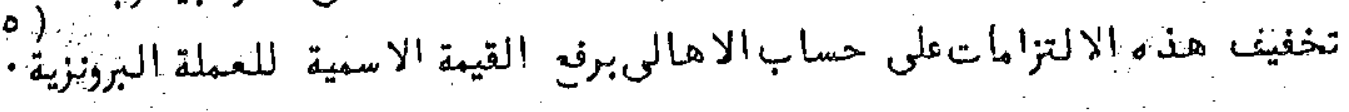
قرارات عفو بطليهوس الثاهن

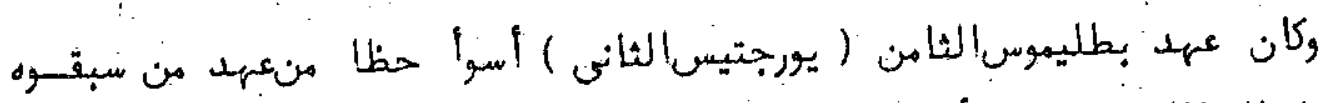

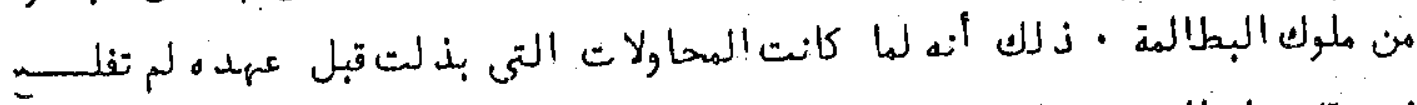

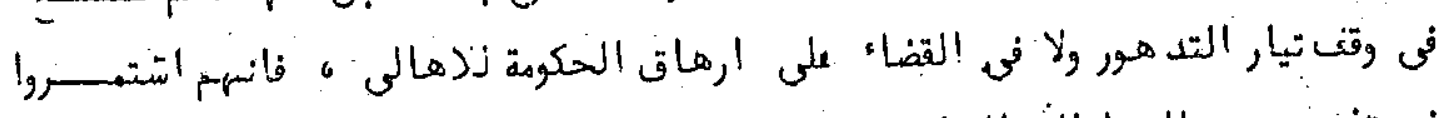

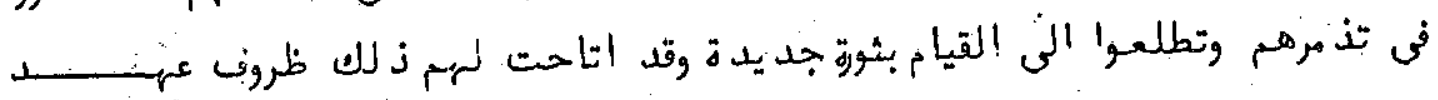

(1) Diod.,31, 15a; P. Amh., 30.

(2) U.P.Z., 122, 9.

(3) U.P.Z., 71, 7

(4) P. Tebt., 742, 11. $26 \mathrm{ff} ., 32 \mathrm{ff}$.

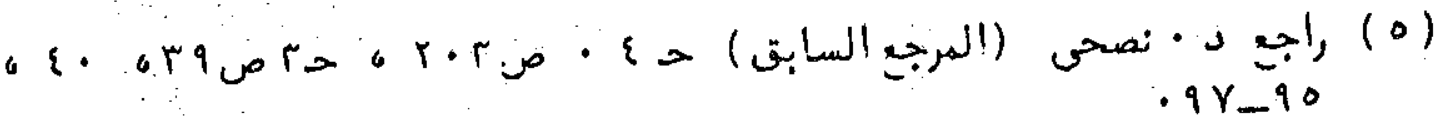




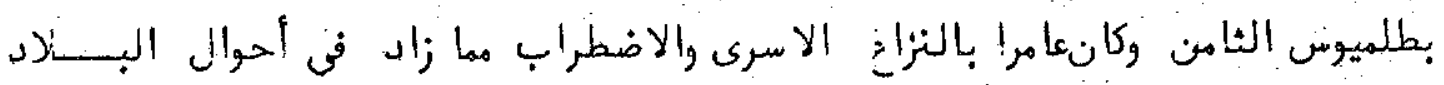

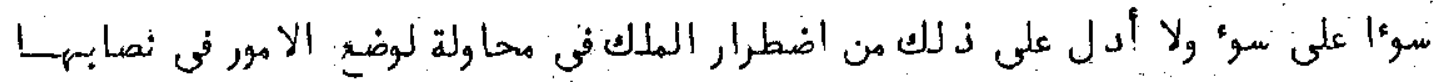

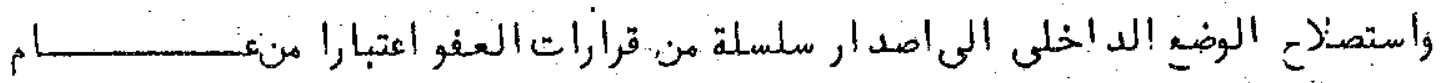

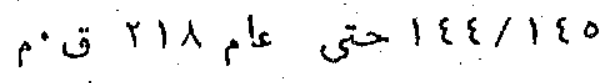
: أ

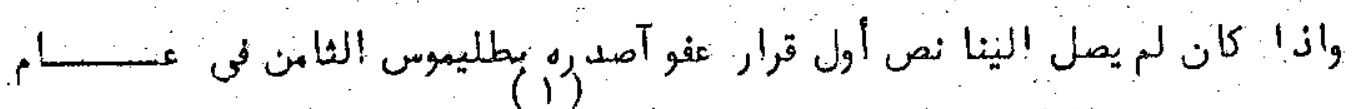

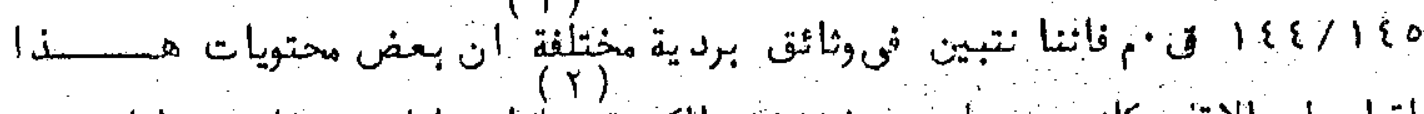

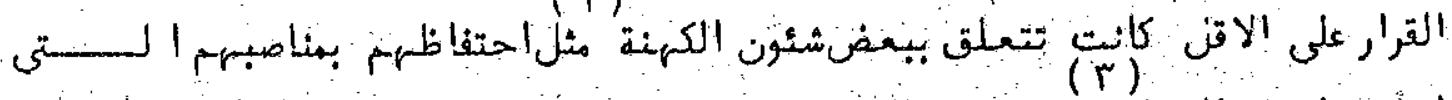

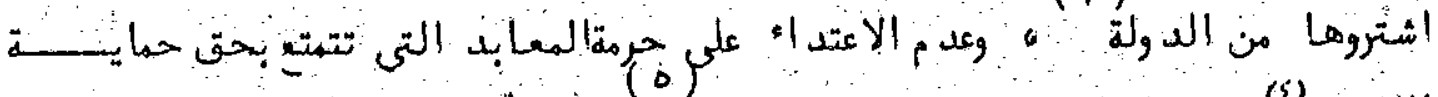

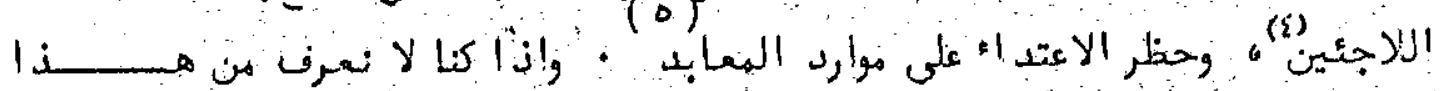

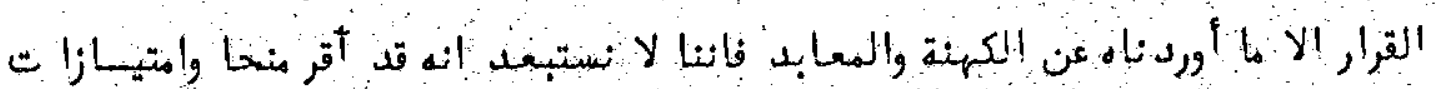

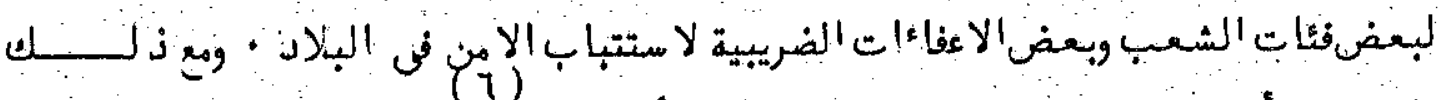

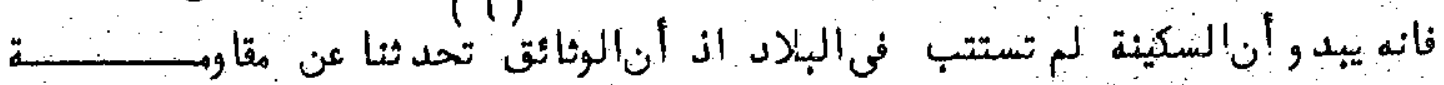

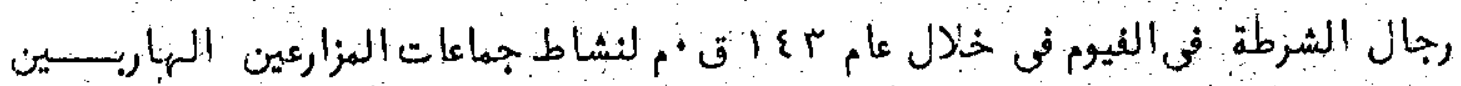

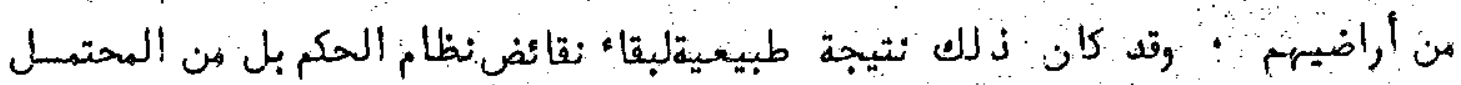

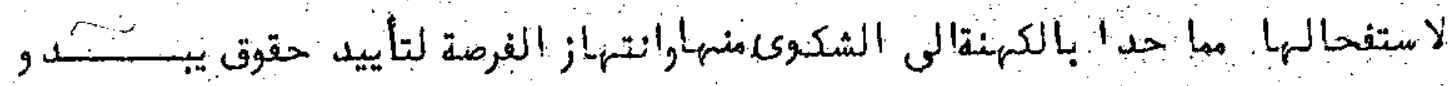

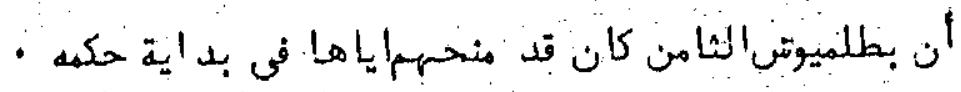

(1) U.P.Z., 161, Col. $3 \mathrm{EF}, 162, \operatorname{Col} .5,21 ; \operatorname{Col} .9 .21$;

P. Tebt., 699; U. Wilcken, Achiv. Pap.. XI, 1933.

P. 149

(2) Cf. P. Tebt., III, Vol (1), P. 137.

(3) P. Tebt.; 699, 11:1-2

(4) P. Tebt., 699, 11, 15-17.

(5) P. Tebt., 699, 11, 18-21.

(6) V. Martin, Les Papyrvs et I'Histoire Adm. de l'E., PP. 144.ff. 


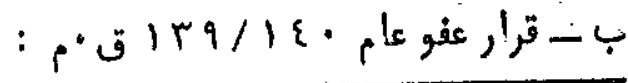

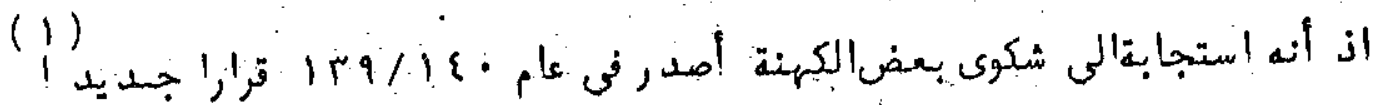

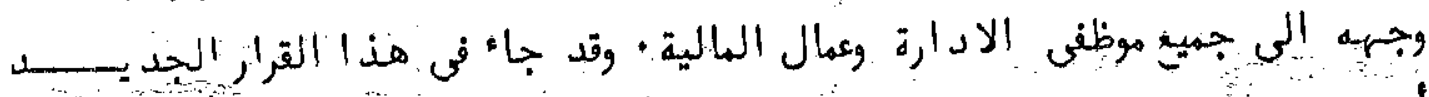

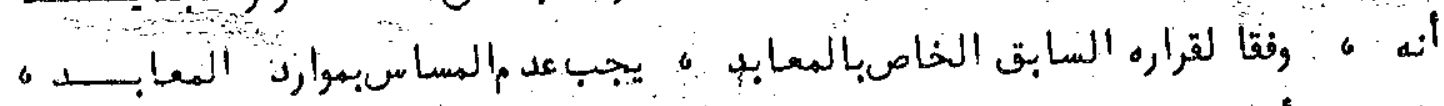

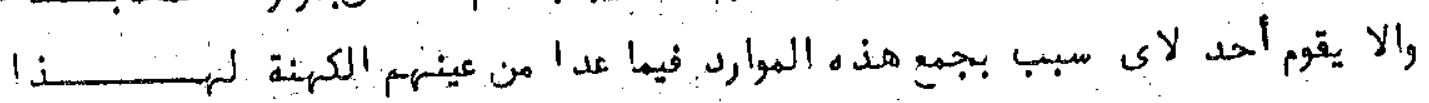

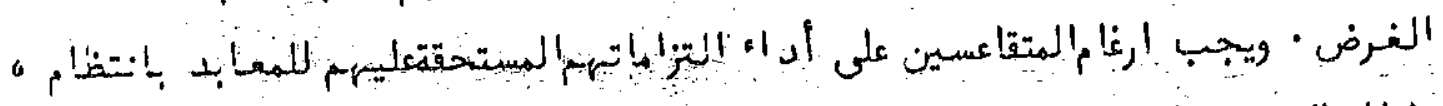

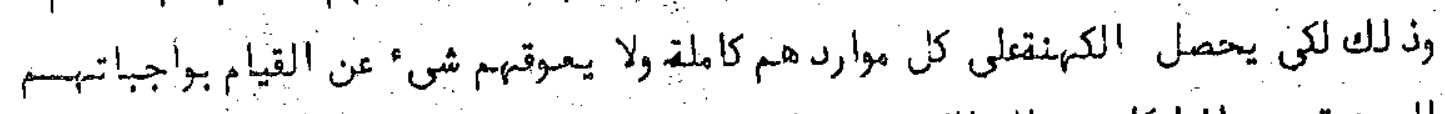

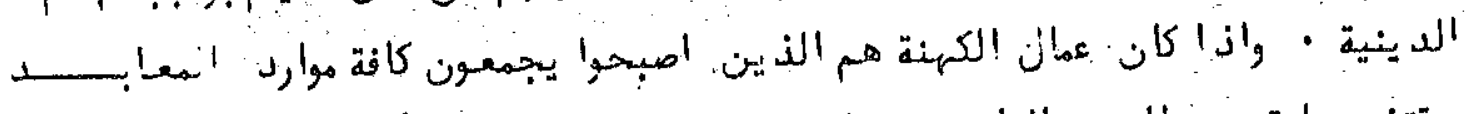

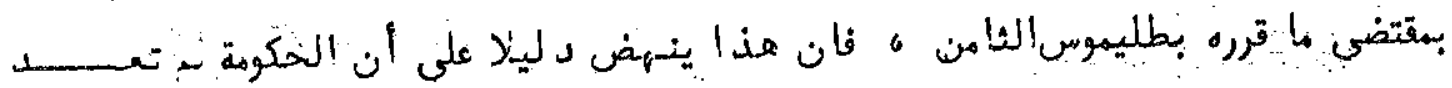

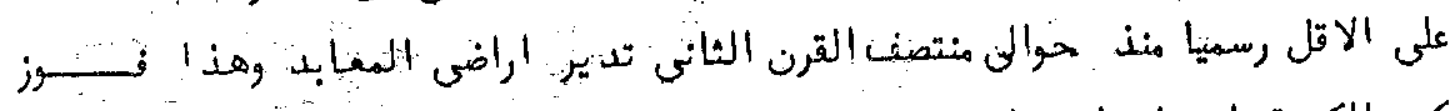

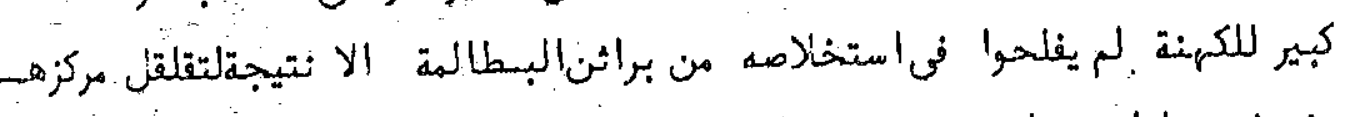

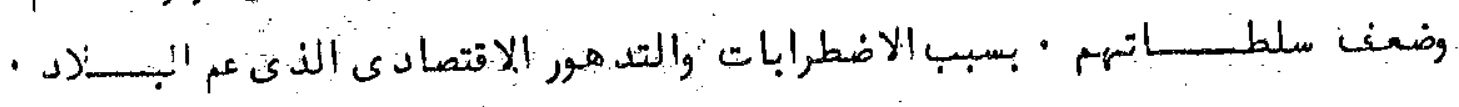

$$
\text { : }
$$

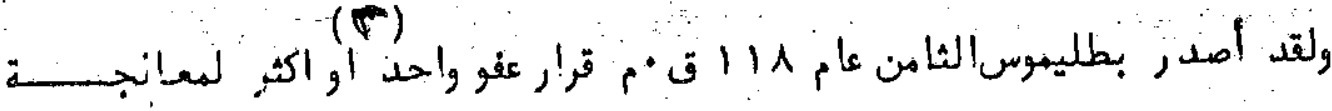

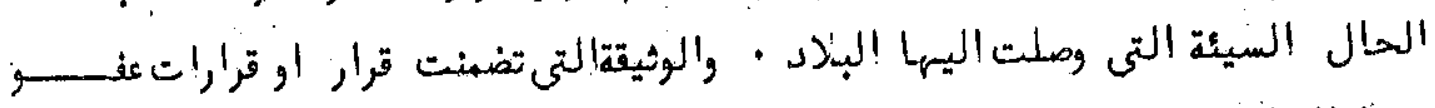

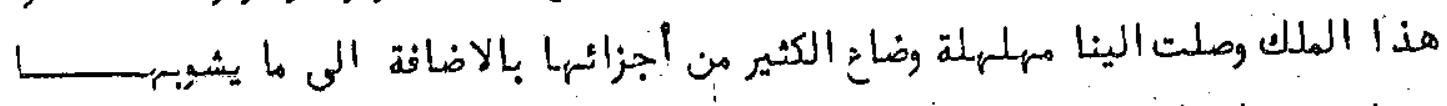

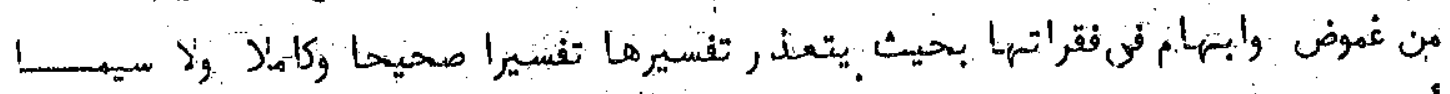

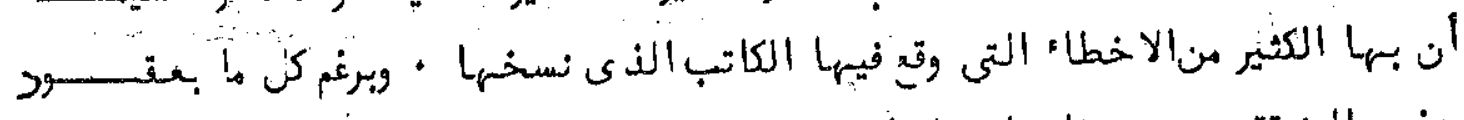

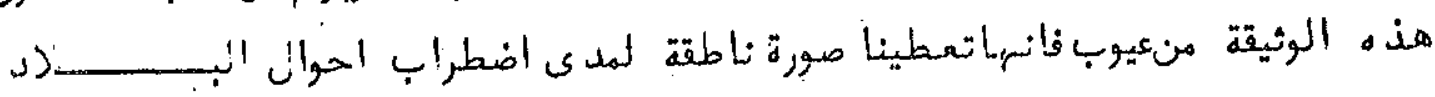

(1) P. Tebt, , 6 .

(2) P. Tebt., 5 . 


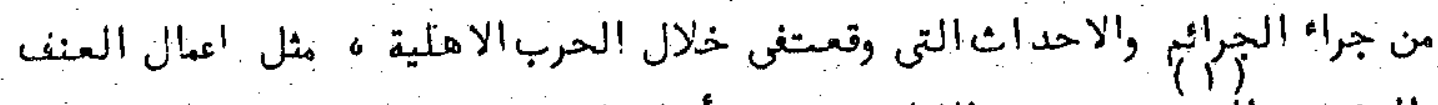

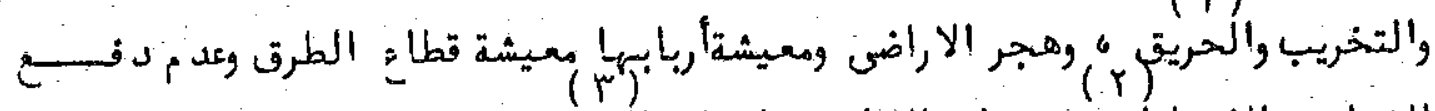

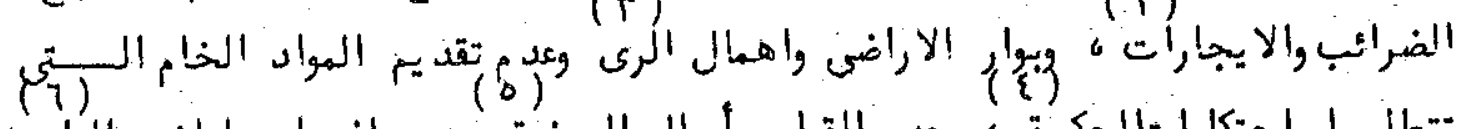

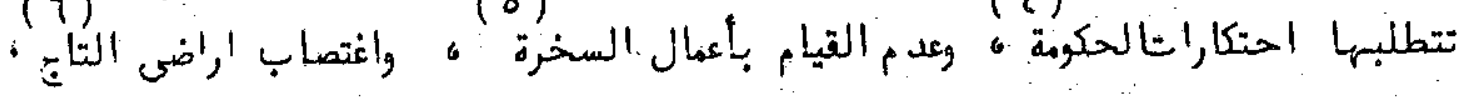

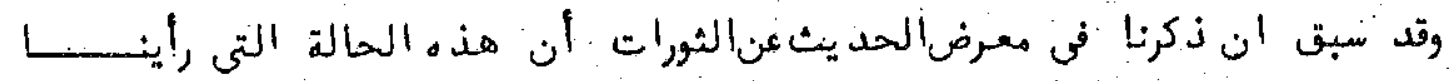

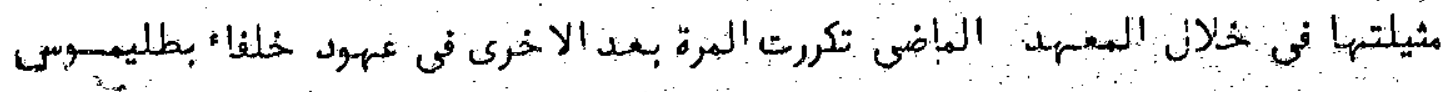

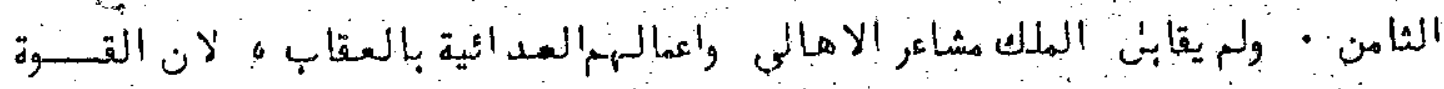

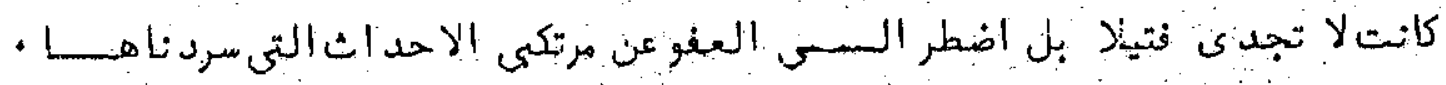

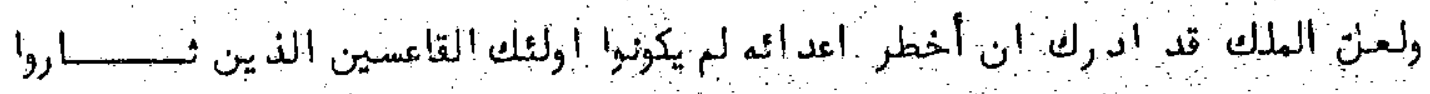

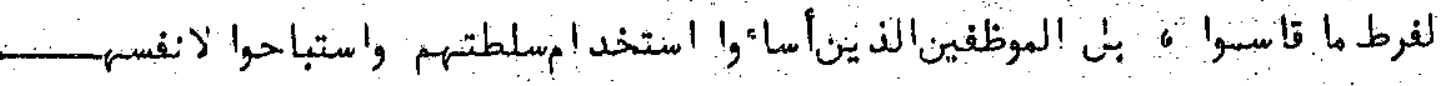

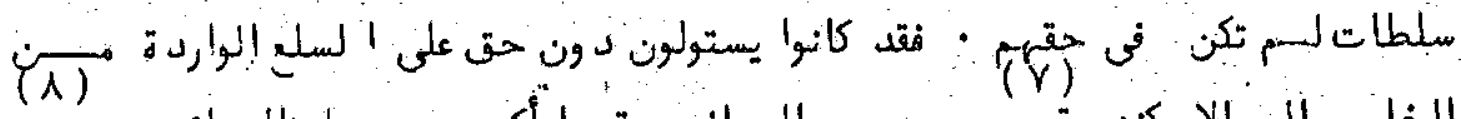

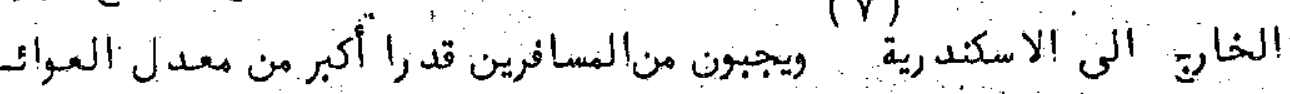

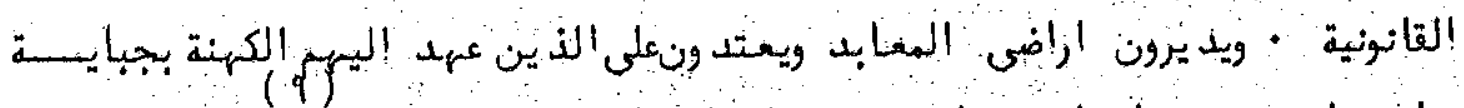

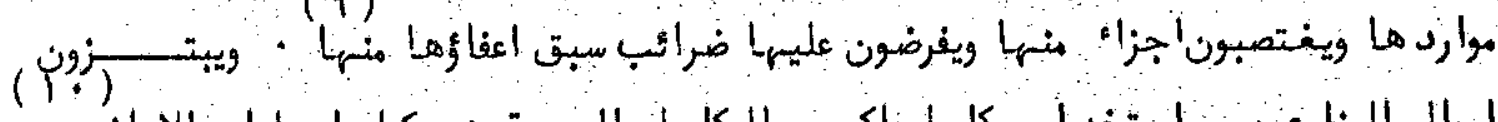

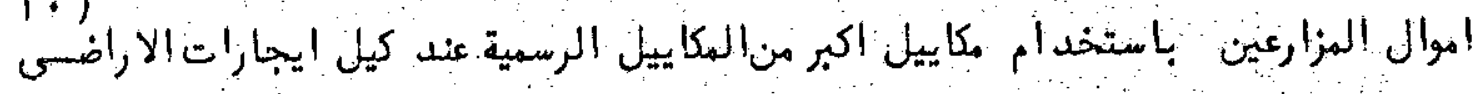

(1) P. Tebt., 5, 11, 134-8, 147-54.

(2) P. Tebt., 5, 11, 5-24.

(3) P. Tebt., 5, 11, 93-8.

(4) P. Tebt., 5, 11, 193-7

(5) P. Tebt., 5, 11. 198-9.

(6) P: Tebt., 5, 11. 36-58.

(7) P. Tebt., 5, 11, 25-7.

(8) P. Tebt., 5, 11, 28-36.

(9) P. Tebt., 5, 11, 45-72.

(10) P. Tebt., 5, 11, 85-92. 
(r)

(1)

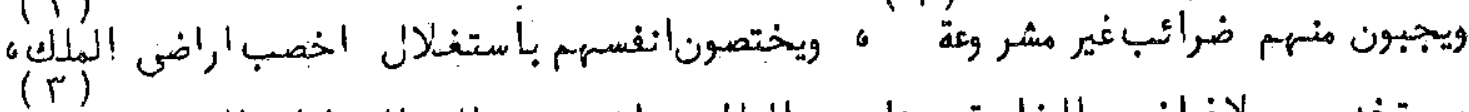

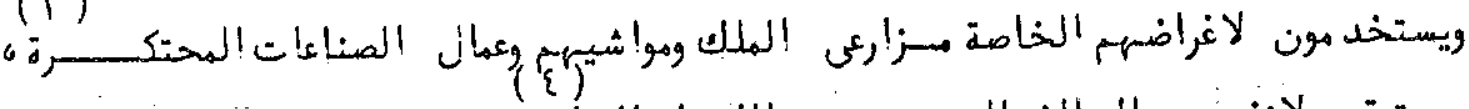

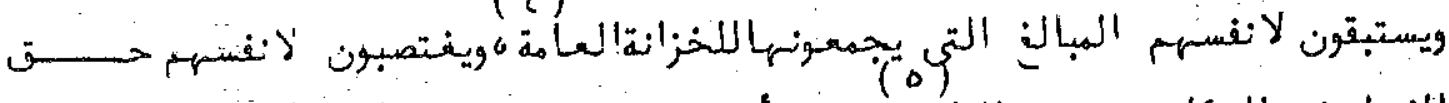

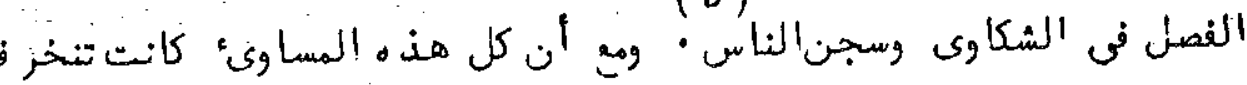

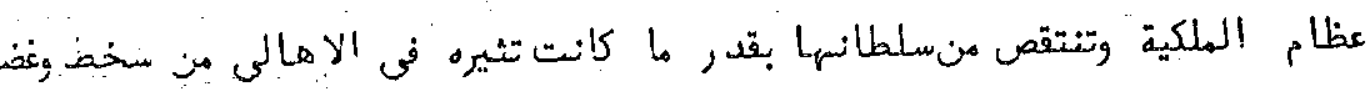

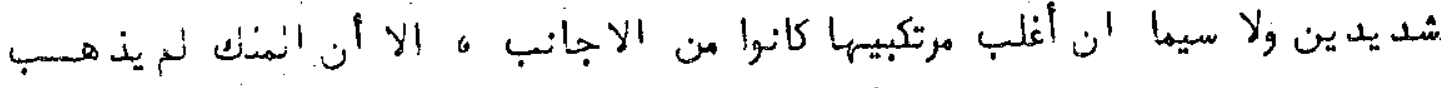

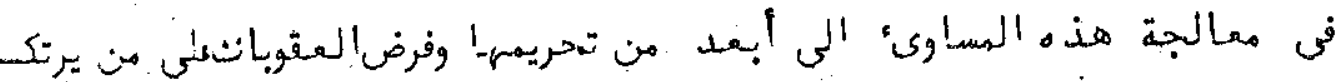

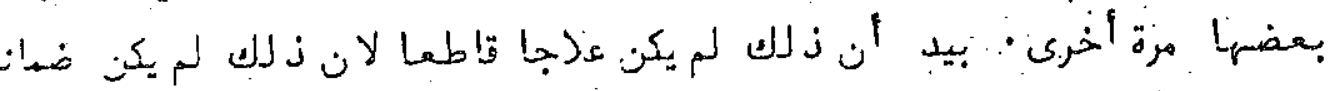

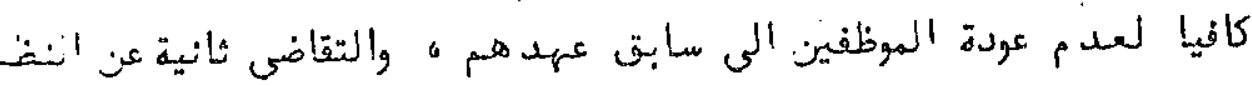

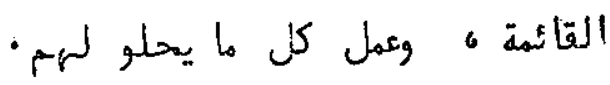

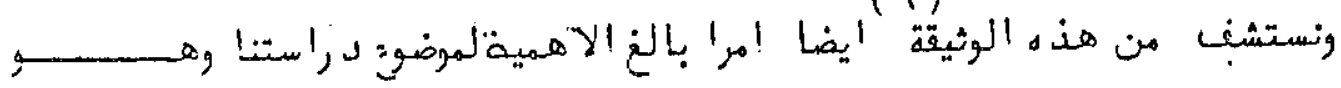

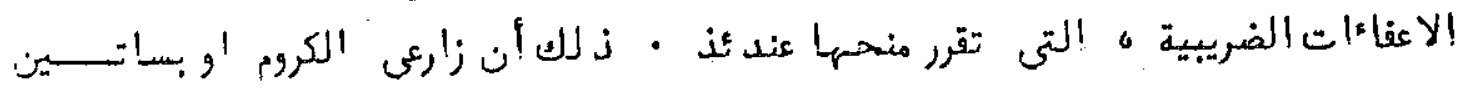

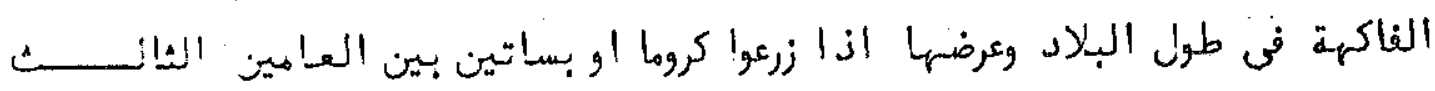

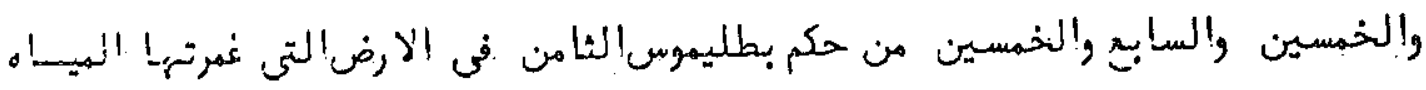

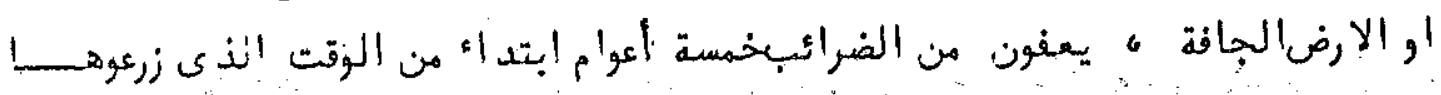

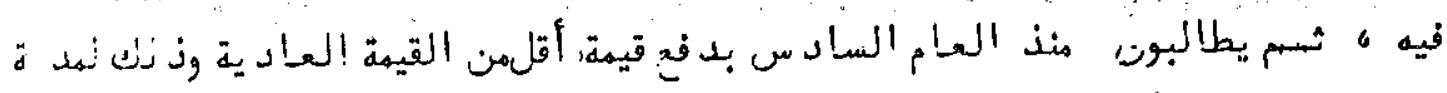

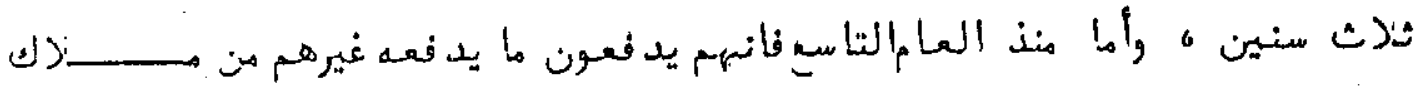

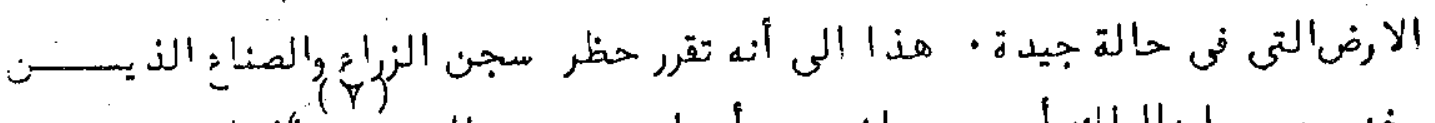

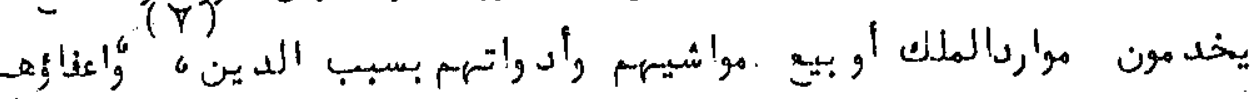

(1) P. Febt., 5, 11, 133-43=155-61.

(1) P. Tebt., 5, 11, 144-6 = 162-7.

(2) P. Tebt., 5, 178-97, 218-54.

(3) P. Tebt., 5, 188-92.

(4) ?. Iebt.,5, 11. 235-54.

(5) P. Tebt., 5.

(G) 2. Tebt., 5, 11:93-98.

(7) P. Tebt., 5, 11, 221-247. 


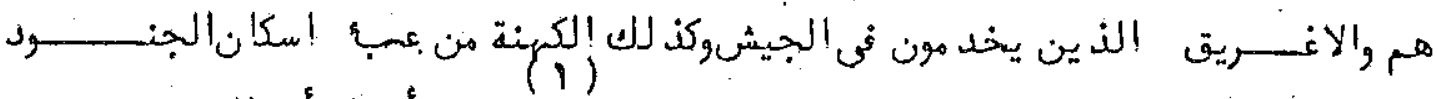

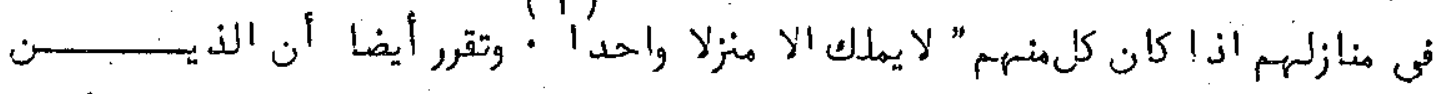

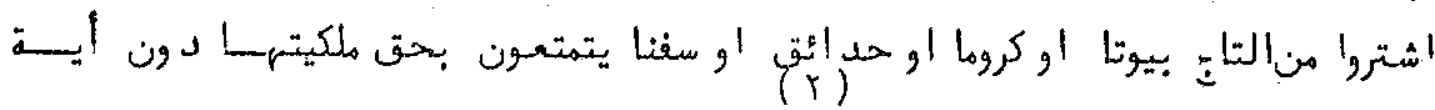

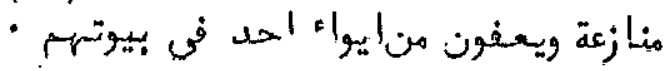

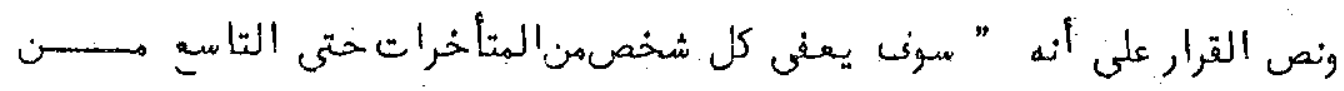

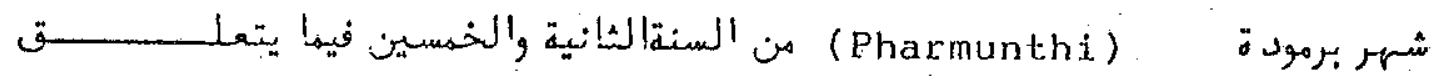

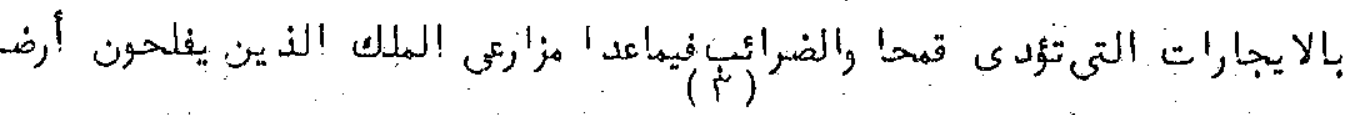
بمقتضى عقود وراثية

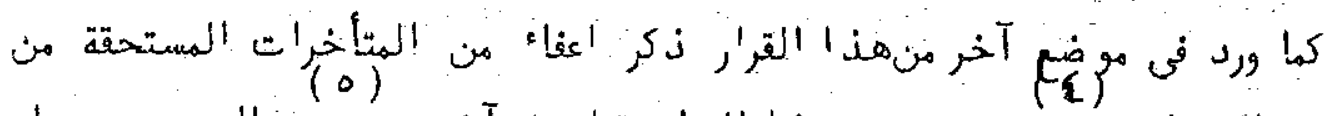

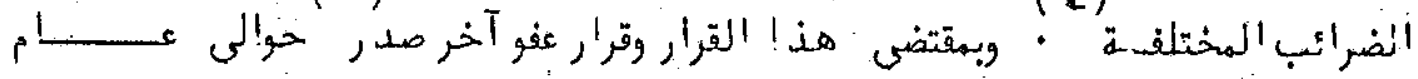

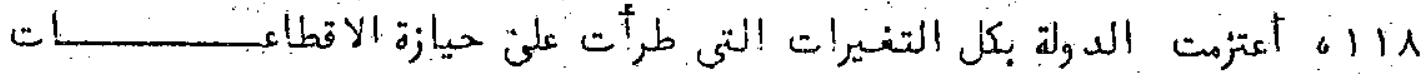

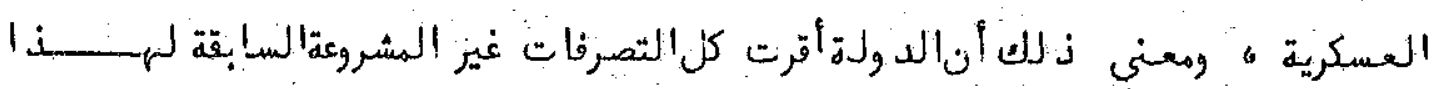
التاريخ

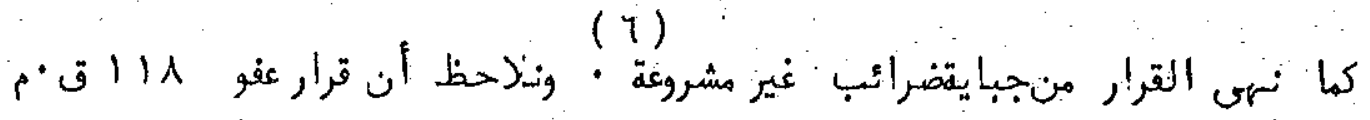

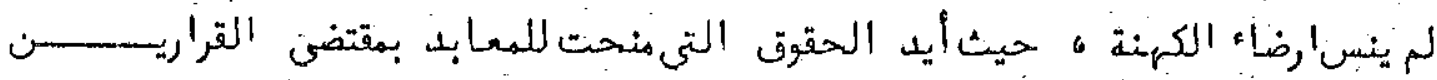

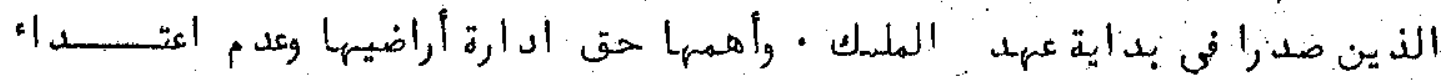

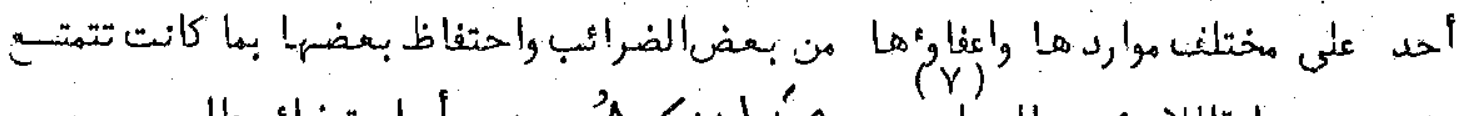

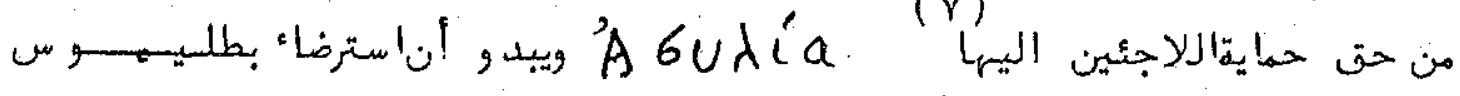

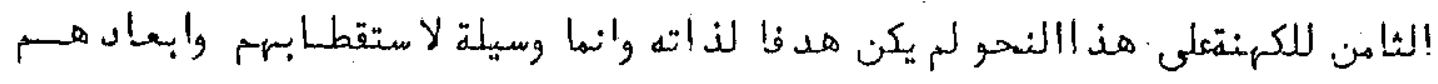

(1) P. Tebt., 5, 11. 168-77.

(2) P. Tebt., 5, 11.99-101.

(3) P. Tebt., 5, 11, 10-13.

(4) P. Tebt., 5, 11, 14-26.

(5) P. tebt., 5, 11. 44-8; P. Tebt., 124, 11. 25 ff.

(6) P. Tebt., 5, 1. 166; P. Ryl., IV, P. 30, Not. 5.

(7) P. Tebt., 5, 11. 54-84. 


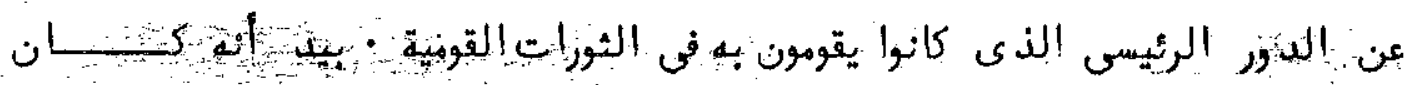

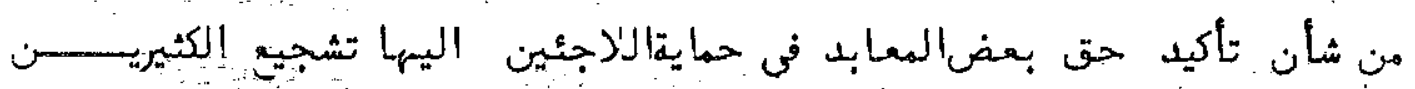

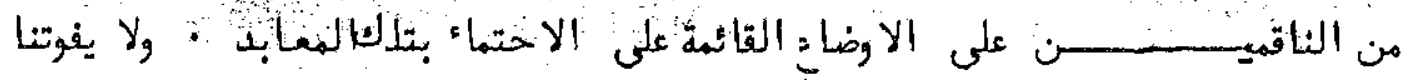

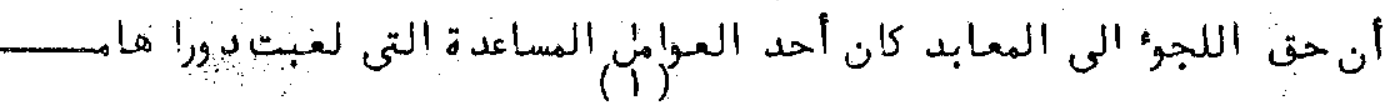

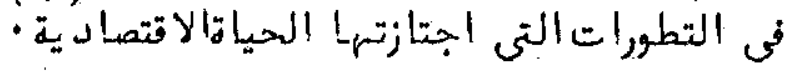

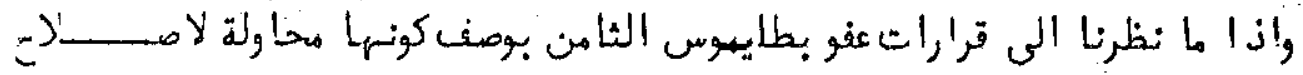

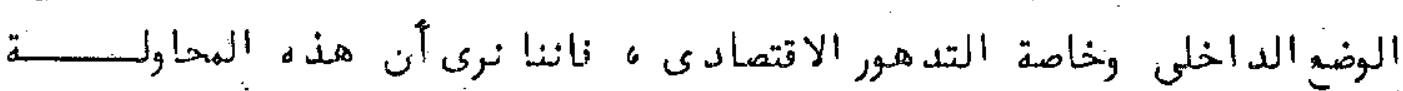

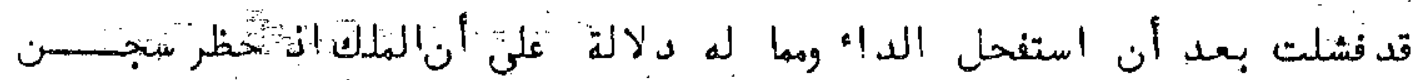

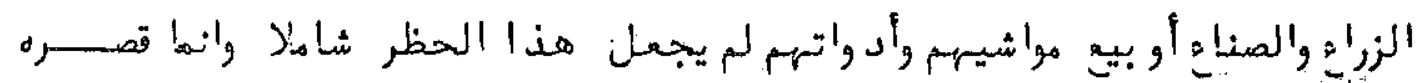

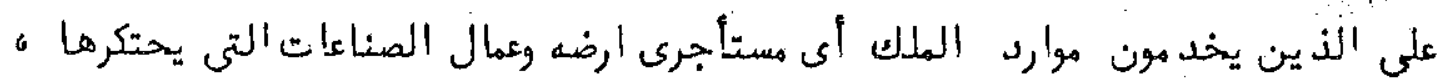

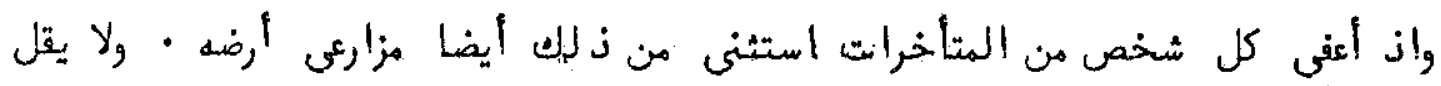

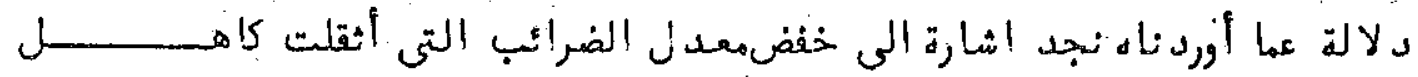

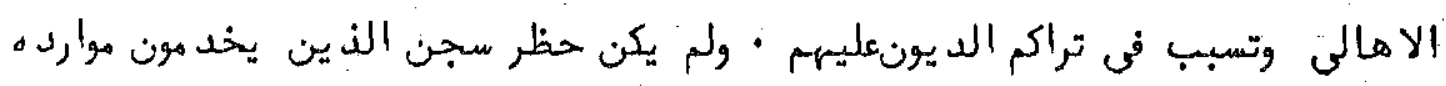

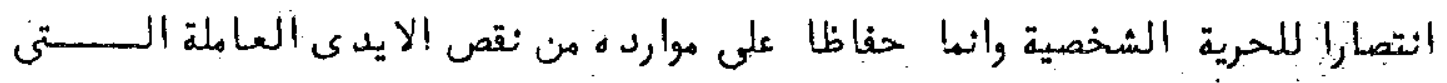
- تبذدodr

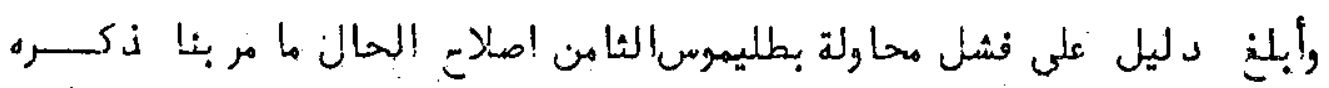

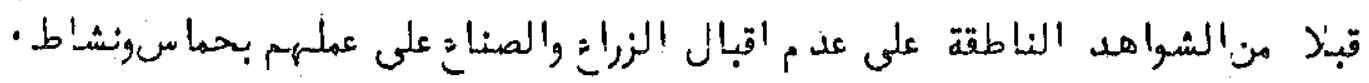

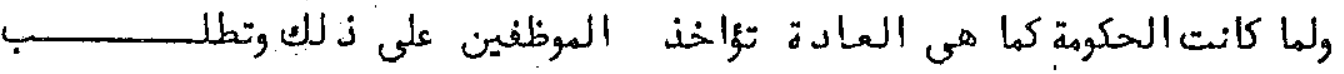

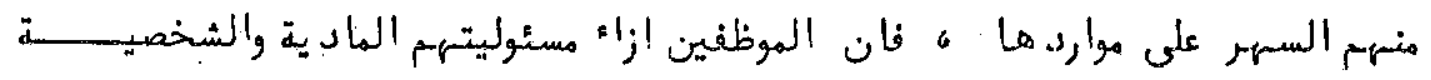

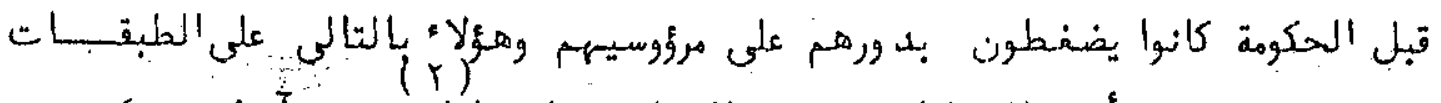

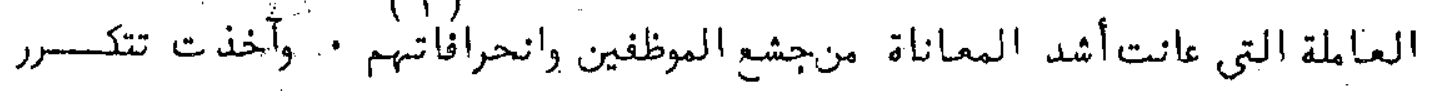

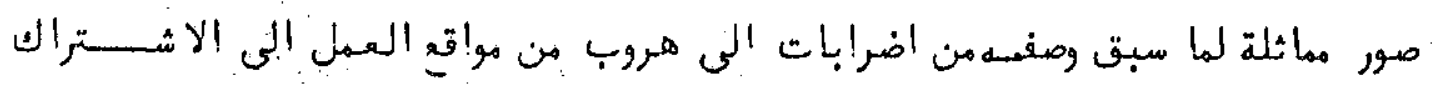
في إلثورات كلما سنحت الفرصة

(1) M. Rostovtzeff, Soc, and Ec., PP. $399+903$.

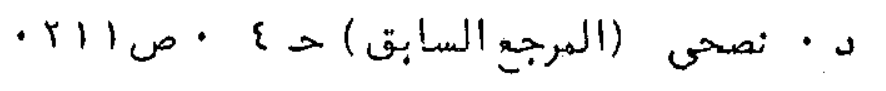


ولقد زادت حالة البيلالد سوءا على سو: بعد وفاة بطليهوس الثامن عبـام 117

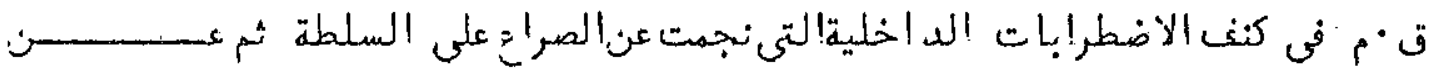

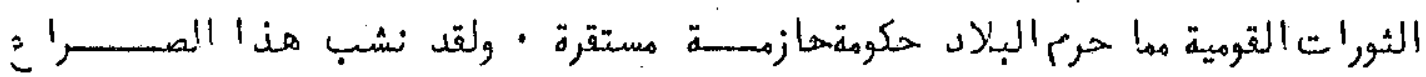

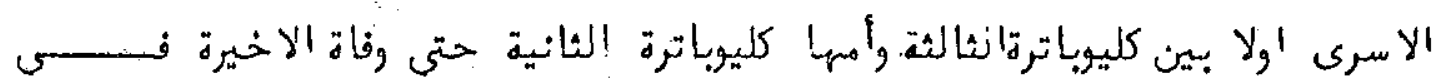

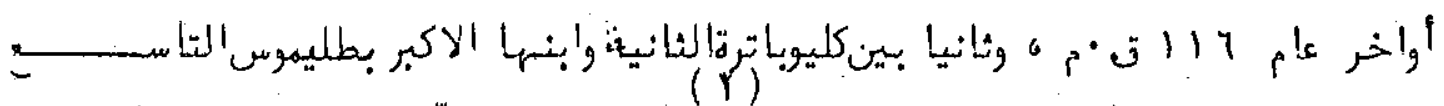

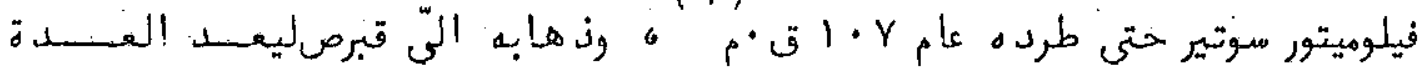

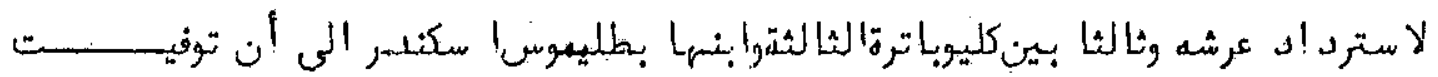

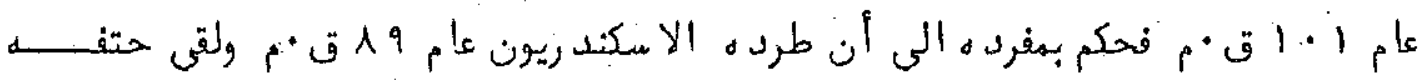

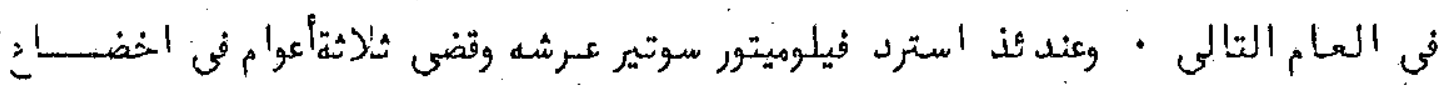

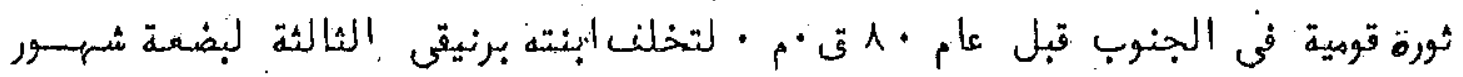

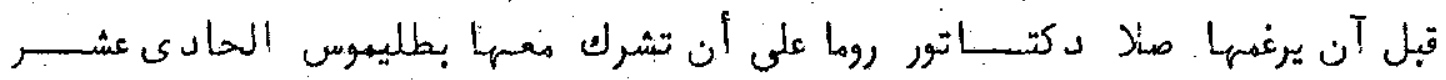

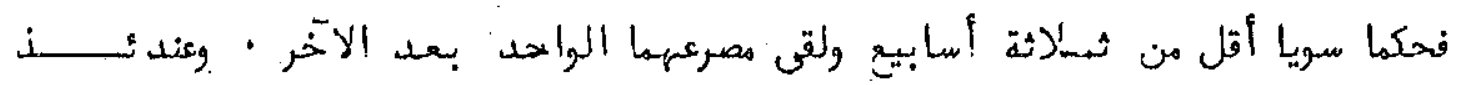

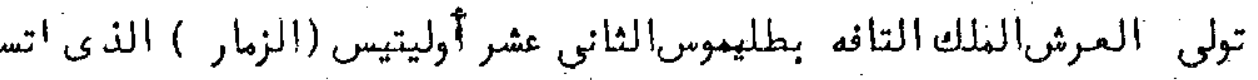

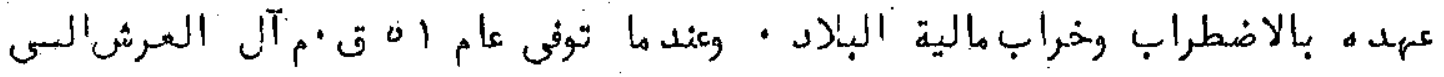

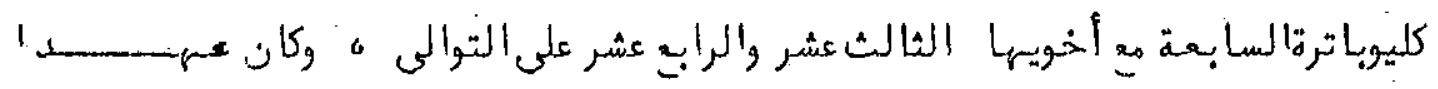

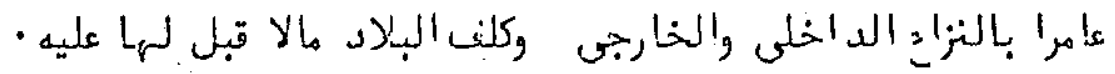

والم يكن من شأن الصراغ على السلطة ولا نشوب الثوراتالقومية ولا ضياء قوربنائية

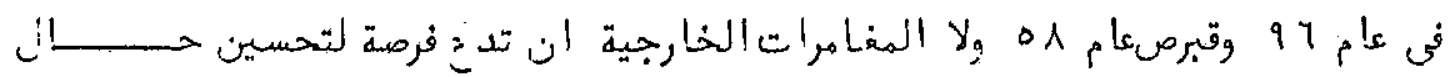

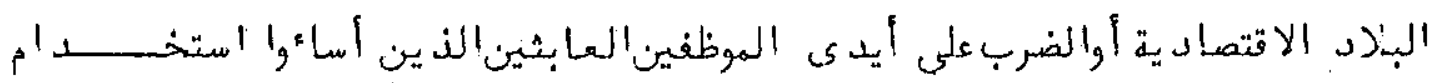

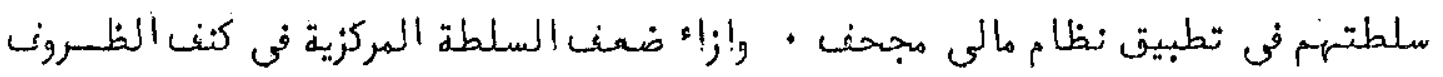

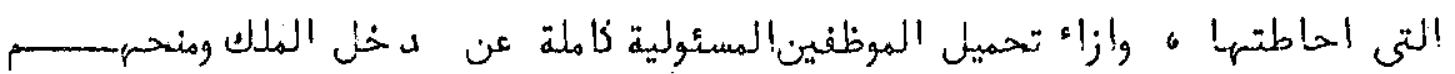

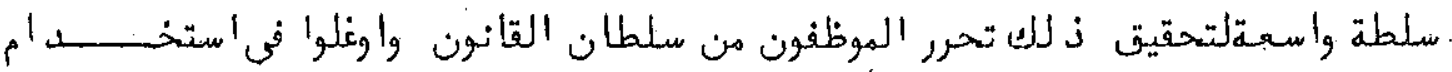

(1) Justin., XXXIX, 3,1; 5,2. 


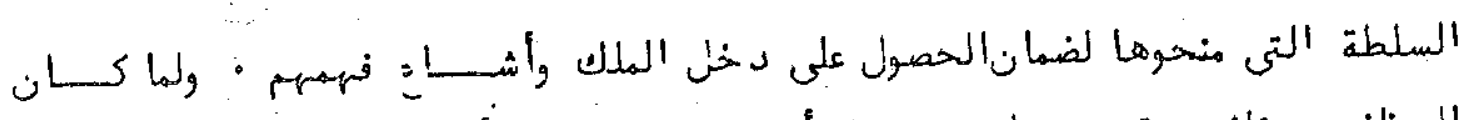

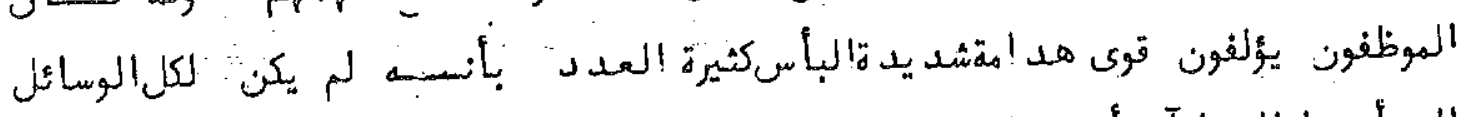

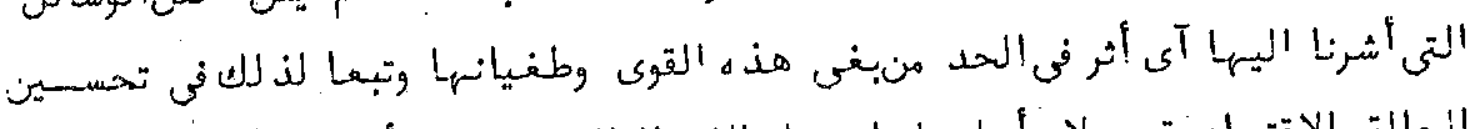

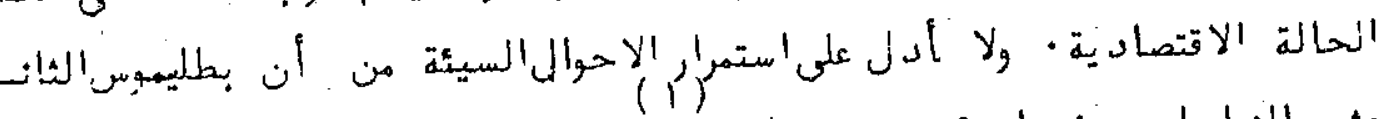

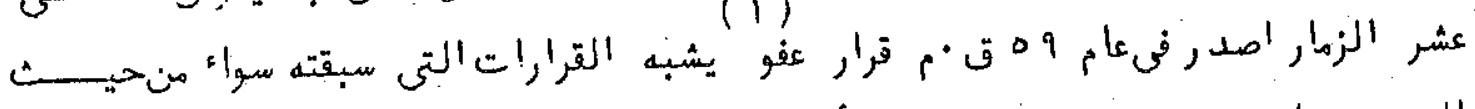

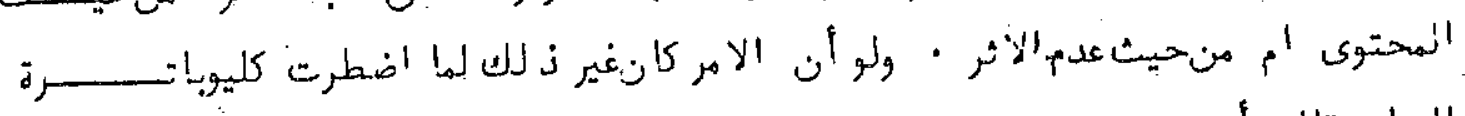

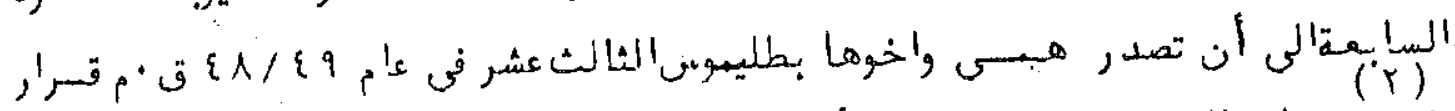

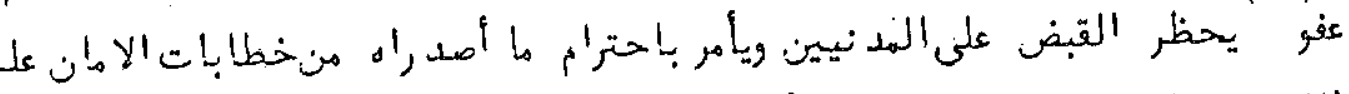

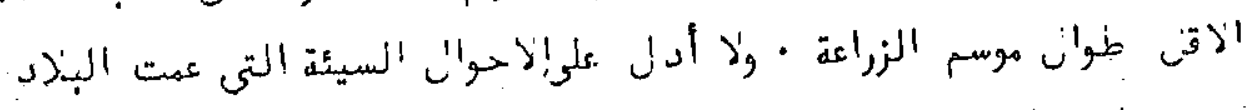

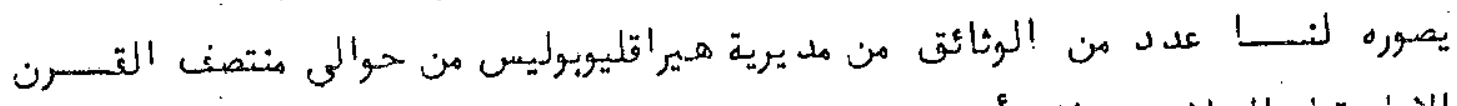

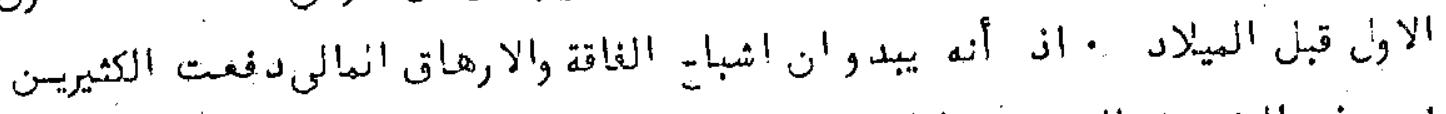

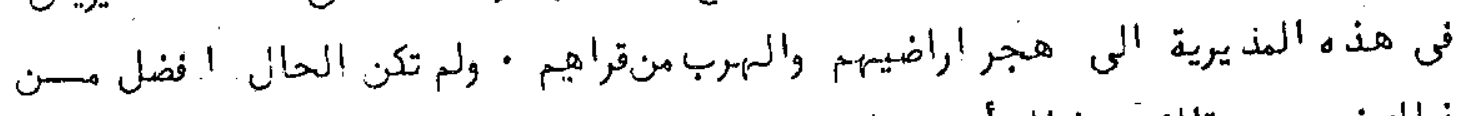

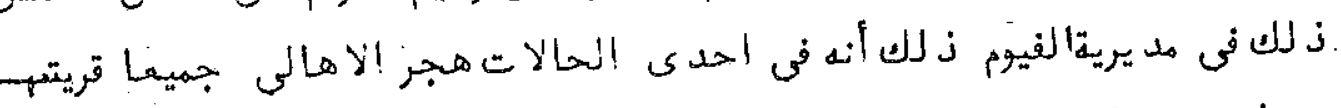

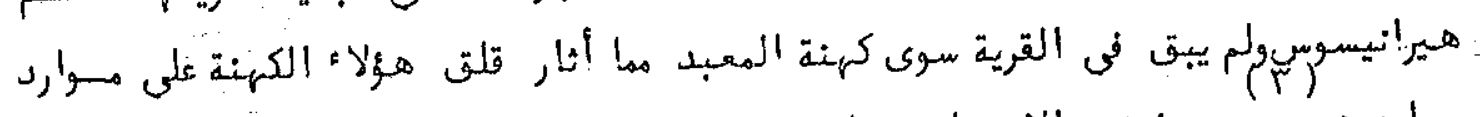

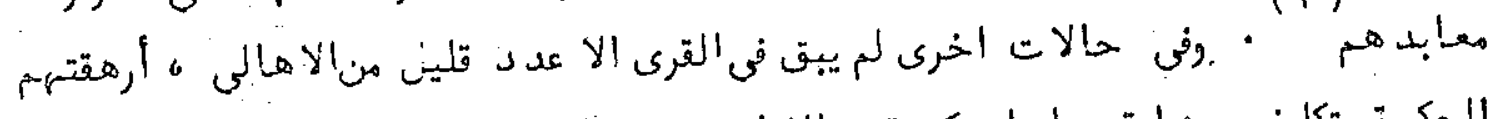

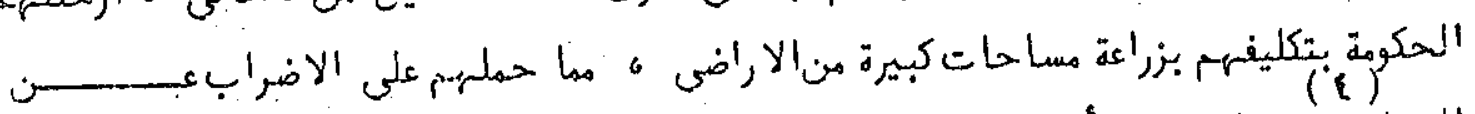

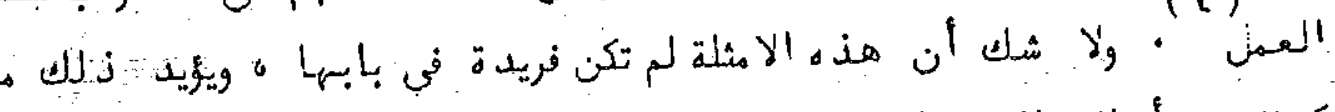

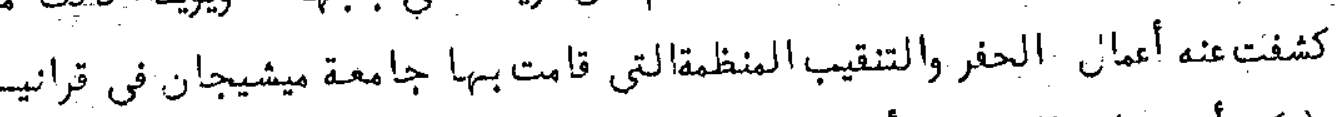

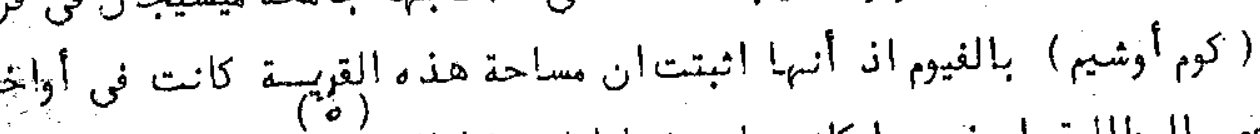

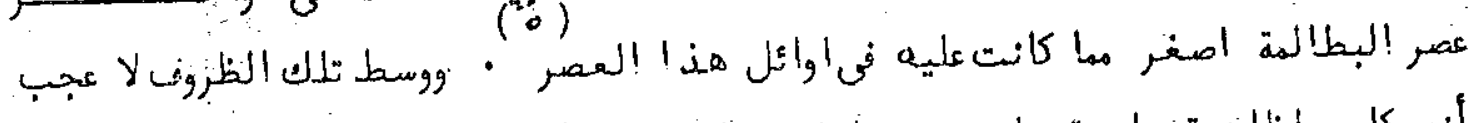

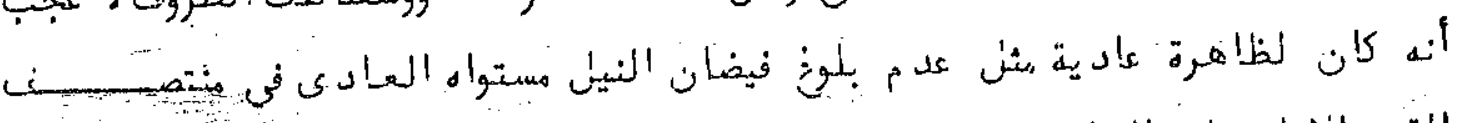

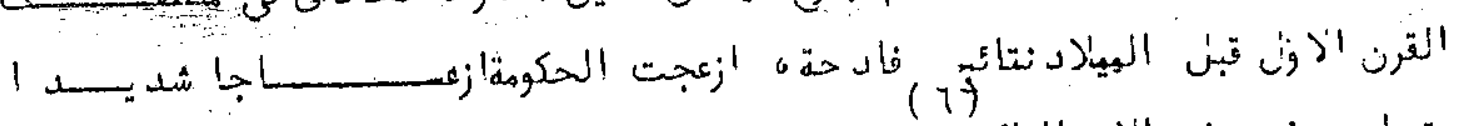

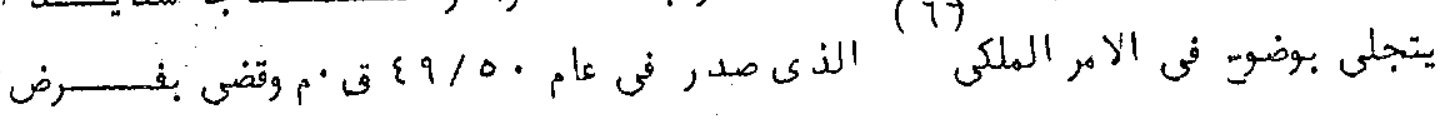

(1) B.G.U., 1185 (59.B.C.)

(2) B.G.U., 1812,, (49/48 B.C.)

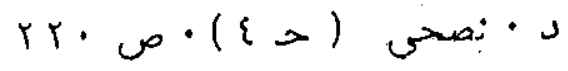

(3) B.G.U., $1835(51 / 50$ B.C.)

(4) B.G.U., $1815(61 / 60) ; 1843(50 / 49)$.

(5) M. Rostovtzeff, Soc. and Ec., PP. 908-9.

(6) B.G.U., 1730. 


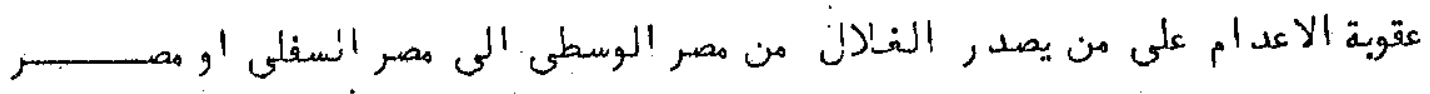

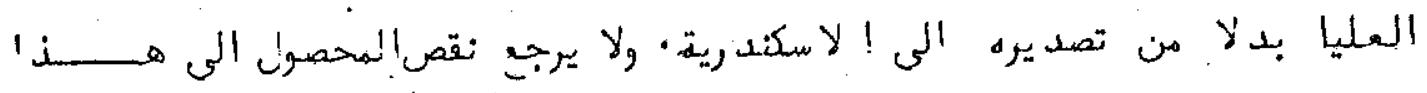

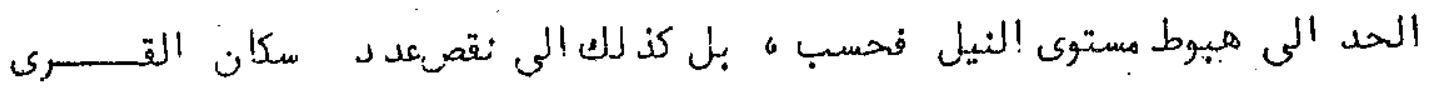

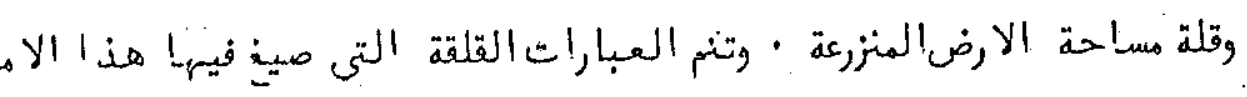

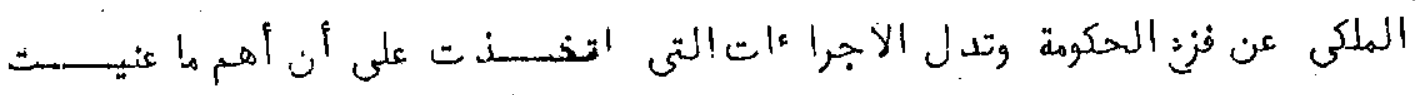

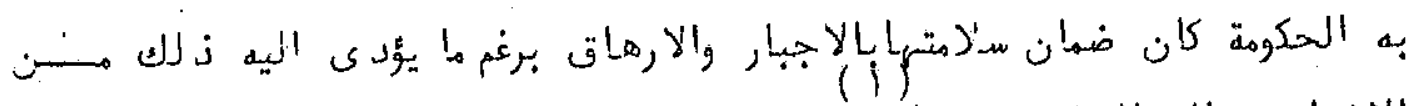

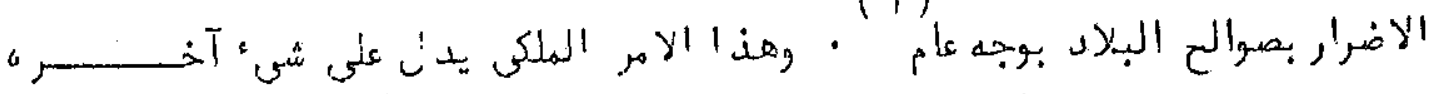

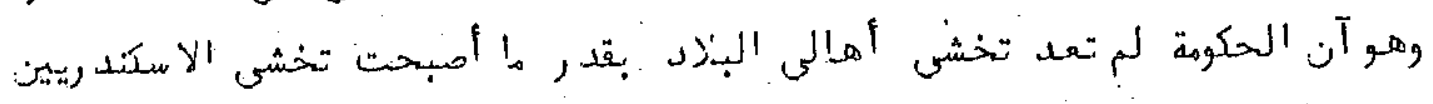

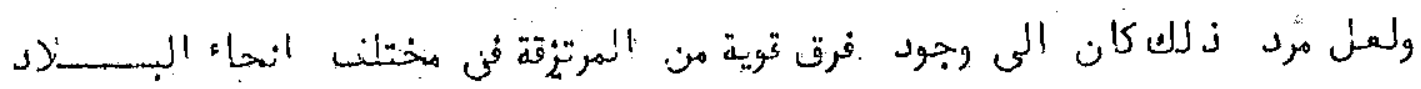

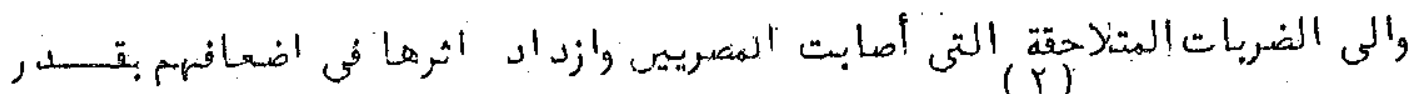

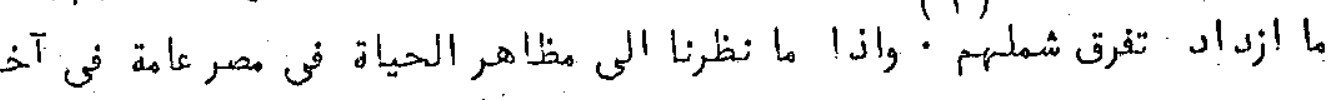

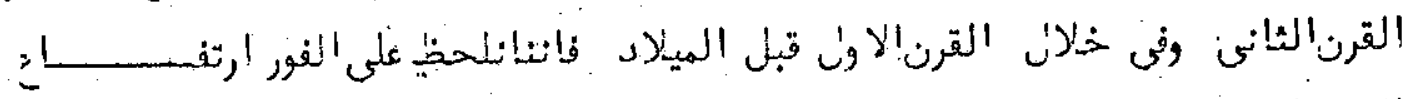

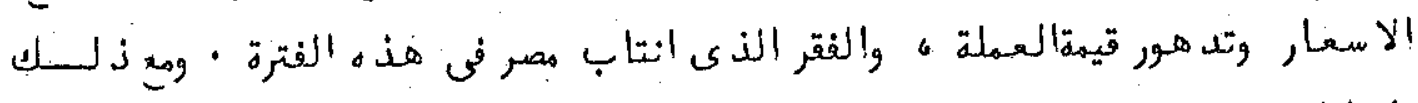

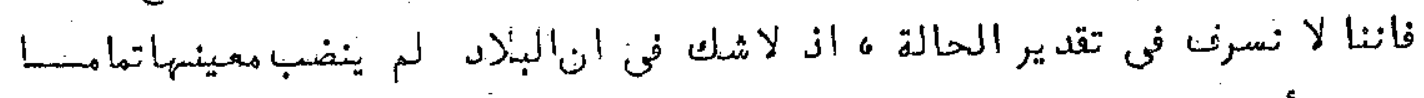

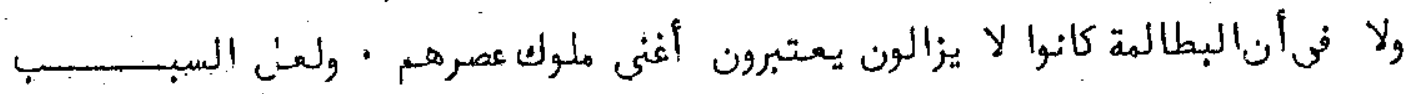

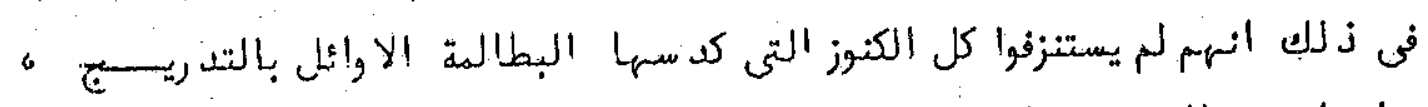

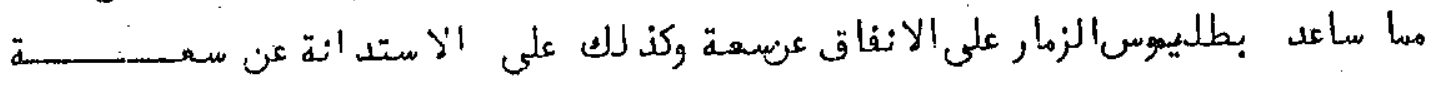

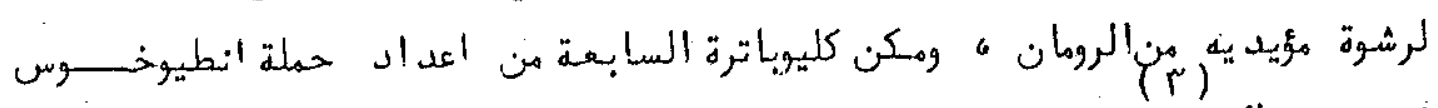

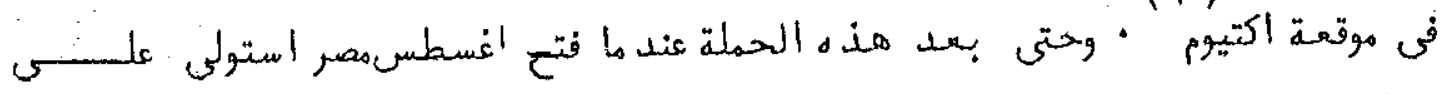

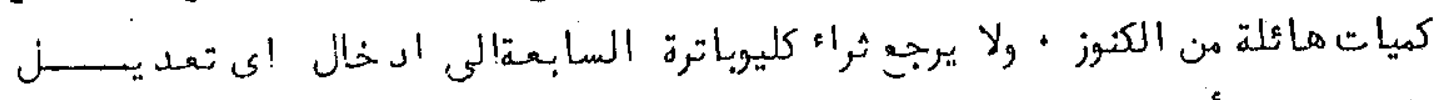

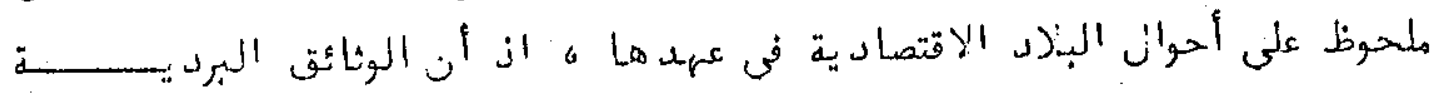

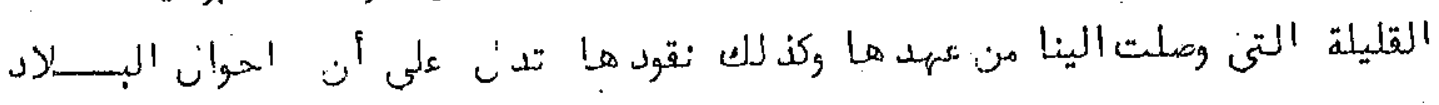

(1) M. Rostovtzeff, Soc., and EC, P. 909 .

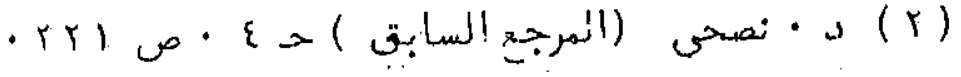

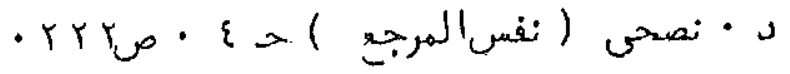


(1)

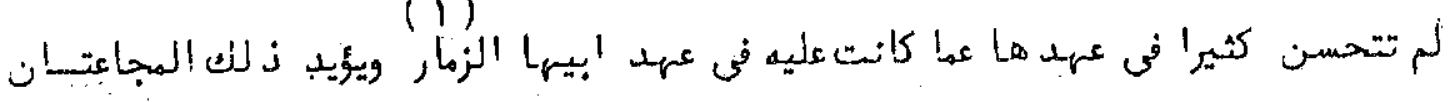

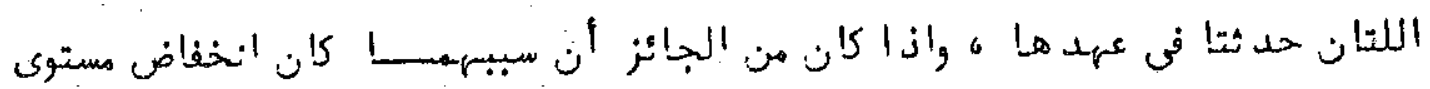

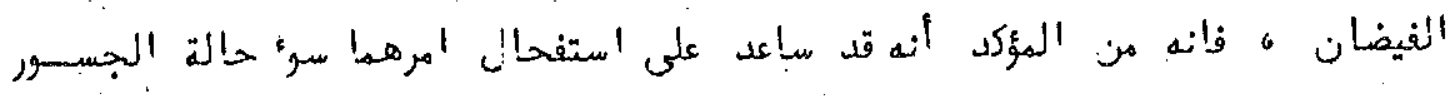

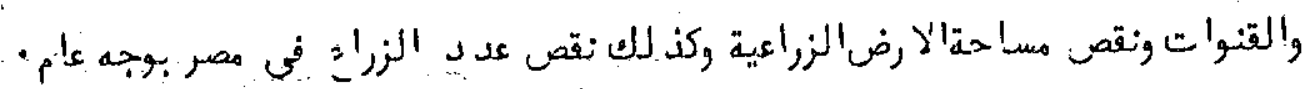

(1) M. Rostovtzeff, Soc. and E.., PP. 909-10. 